
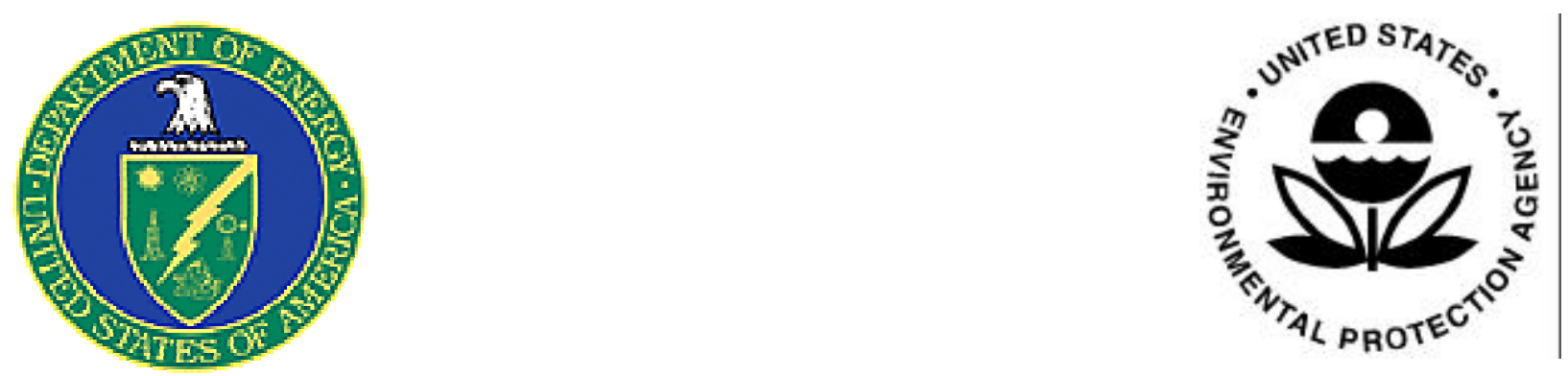

\title{
DECISION SUPPORT SOFTWARE TECHNOLOGY DEMONSTRATION PLAN
}

\section{September 1998}

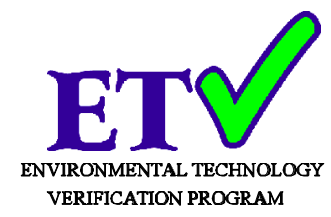

\section{Sponsored by}

U.S. Environmental Protection Agency National Exposure Research Laboratory

Las Vegas, NV 89193-3478

and

U.S. Department of Energy

National Analytical Management Program

Idaho Falls, ID 83401

Prepared by:

Terry Sullivan

Environmental and Waste Management Group

Brookhaven National Laboratory

Brookhaven Science Associates

Upton, NY 11973

and

Anthony Armstrong

Oak Ridge National Laboratory

Lockheed Martin Energy Research Corporation

Oak Ridge, TN 37831-6120 


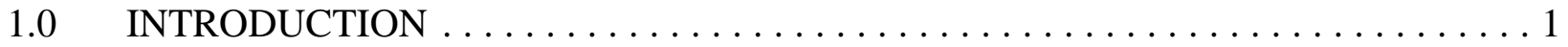

1.1 Decision Support Software Demonstration $\ldots \ldots \ldots \ldots \ldots \ldots \ldots \ldots \ldots$

1.2 Demonstration Objectives . . . . . . . . . . . . . . . . . . . 3

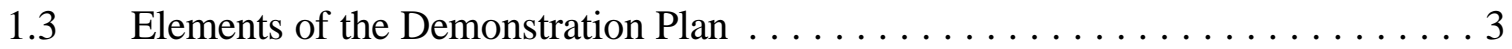

1.4 The Site Characterization and Monitoring Technology Pilot $\ldots \ldots \ldots \ldots \ldots$

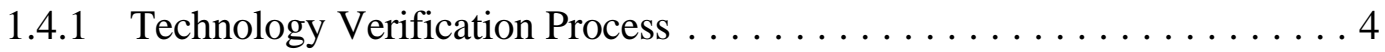

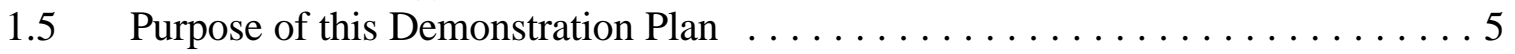

2.0 DEMONSTRATION RESPONSIBILITIES AND COMMUNICATION $\ldots \ldots \ldots 6$

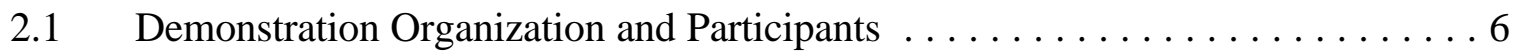

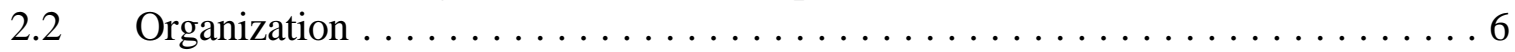

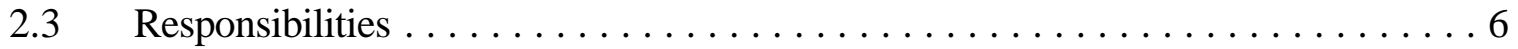

3.0 TECHNOLOGY DESCRIPTION $\ldots \ldots \ldots \ldots \ldots \ldots \ldots \ldots \ldots \ldots \ldots \ldots \ldots$

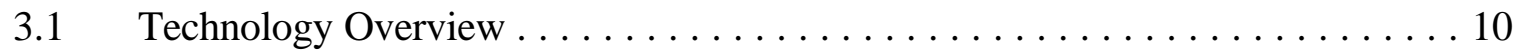

3.1.1 Environmental Systems Research Institute (ESRI) . . . . . . . . . . . . 11

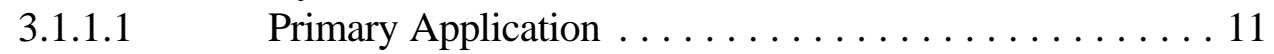

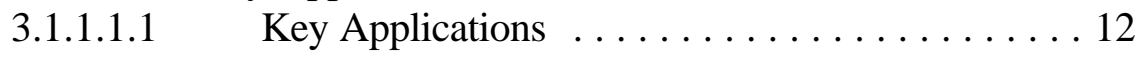

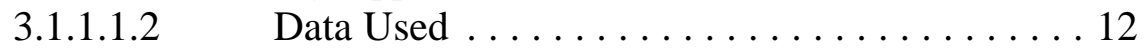

3.1.1.1.3 Cost of the Technology ............ 12

3.1.1.1.4 Training Requirements and User Support . . . . . 12

3.1.1.1.5 Licensing Requirements ............ 13

3.1.1.2 History of ESRI . . . . . . . . . . . . . . 13

3.1.1.3 ARCVIEW Advantages and Operating Parameters . . . . 14

3.1 .2 Environmental Visualization System . . . . . . . . . . . . . 16

3.1.2.1 EVS Hardware System Requirements . . . . . . . . 16

3.1.2.1.1 EVS Software Interfaces $\ldots \ldots \ldots \ldots \ldots \ldots$

3.1.2.1.2 Analytes and Environments ......... 17

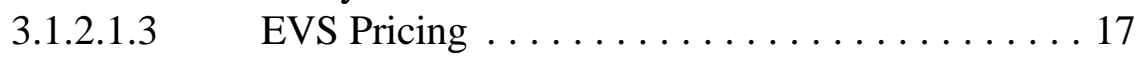

3.1.2.1.4 EVS Training Requirements .......... 18

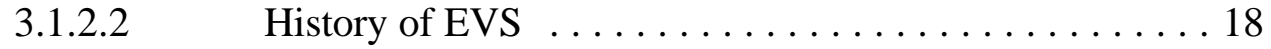

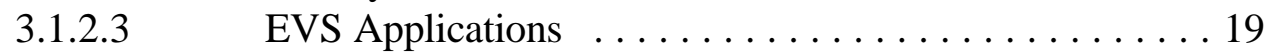

3.1.2.4 Advantages of EVS . . . . . . . . . . . . . 19

3.1.2.5 Operating Parameters of EVS ............ 20

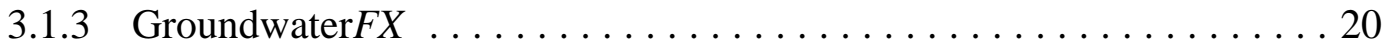

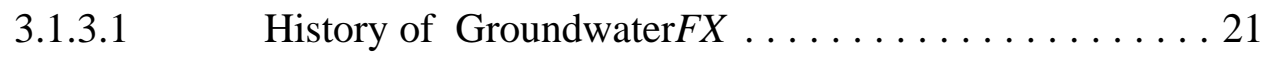

3.1.3.2 Groundwater $F X$ Applications ............... 22

3.1.3.3 Advantages of Groundwater $F X \ldots \ldots \ldots 23$

3.1.3.4 Operating Parameters of Groundwater $F X \ldots \ldots 24$

3.1.4 Spatial Analysis Decision Assistance (SADA) . . . . . . . . . . . . . 24

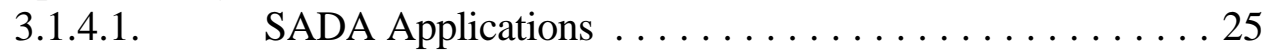

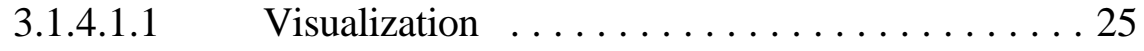

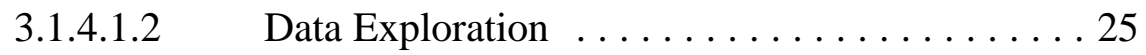


3.1.4.1.3 Human Health Risk . . . . . . . . . . 26

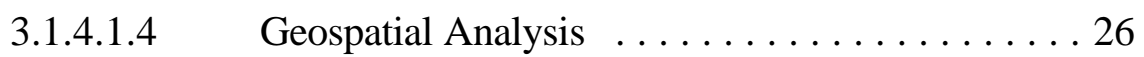

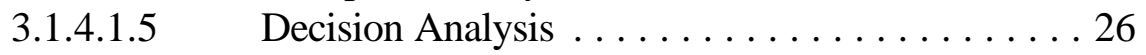

3.1.4.2 Advantages of the SADA Technology . . . . . . . . . 28

3.1.4.3 SADA Operating Parameters . . . . . . . . . . . 28

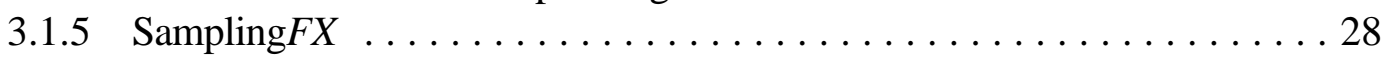

3.1.5.1 History of Sampling $F X \ldots \ldots \ldots . \ldots \ldots$

3.1.5.2 Sampling $F X$ Applications . . . . . . . . . . . . 30

3.1.5.3 Advantages of Sampling $F X \ldots \ldots \ldots \ldots \ldots \ldots \ldots$

3.1.5.4 Operating Parameters of Sampling $F X \ldots \ldots . \ldots 31$

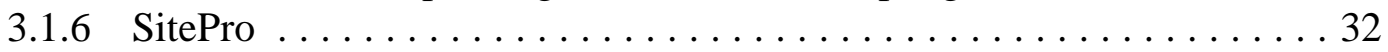

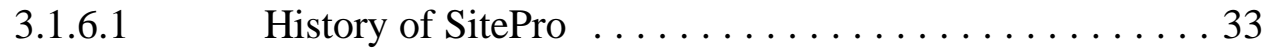

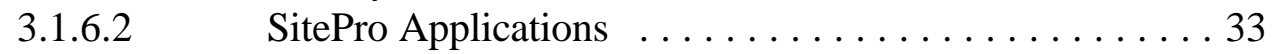

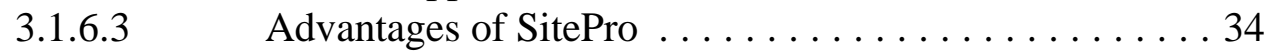

3.1.6.4 SitePro Operating Parameters . . . . . . . . . . 36

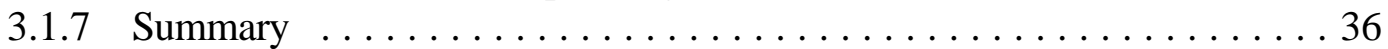

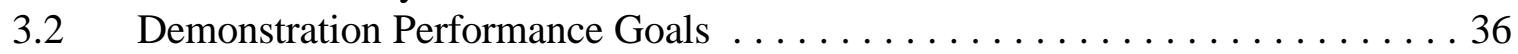

3.2.1 Decision Support . . . . . . . . . . . . . . . . 37

3.2.1.1 Documentation of the Analysis . . . . . . . . . . . 37

3.2.1.2 Presentation of Results . . . . . . . . . . . . . . 37

3.2.1.3 Comparison of Projected Results with the Data . . . . . 38

3.2.1.4 Evaluation of the Use of the Models . . . . . . . . . 38

3.2.1.5 Multiple Lines of Reasoning . . . . . . . . . . . . 38

3.2.2 Documentation of Software . . . . . . . . . . . . . . . . . . . . 39

3.2 .3 Training and Technical Support . . . . . . . . . . . . . . . 39

3.2 .4 Ease of Use . . . . . . . . . . . . . . . . . . . . . 39

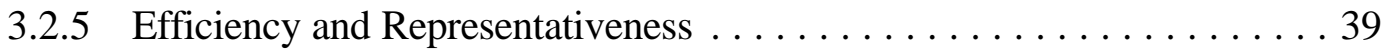

3.2 .6 Flexibility to Interface with other Software $\ldots \ldots \ldots \ldots \ldots \ldots$

4.0 DEMONSTRATION SITE DESCRIPTIONS $\ldots \ldots \ldots \ldots \ldots \ldots \ldots \ldots \ldots \ldots \ldots$

4.1 Site Descriptions and Hydrogeologic Characteristics . . . . . . . . . . . . 41

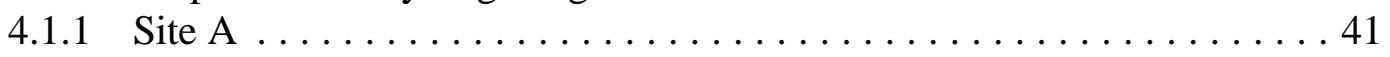

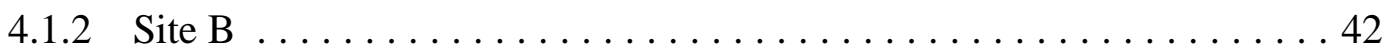

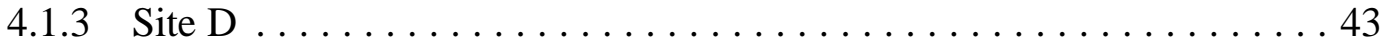

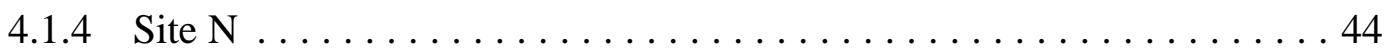

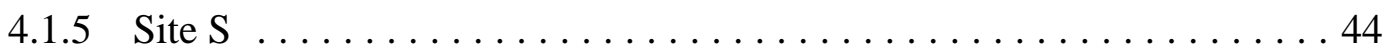

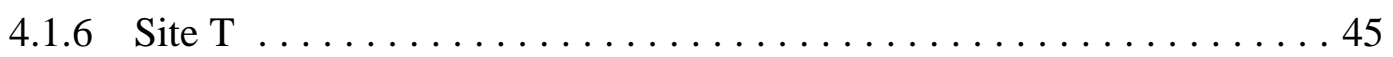

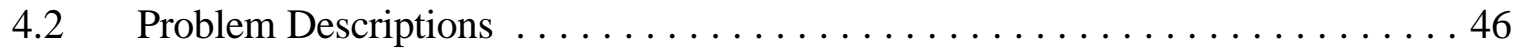




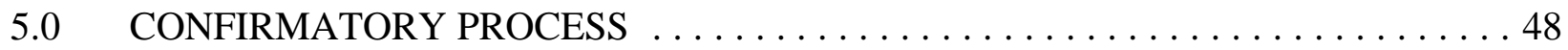

$5.1 \quad$ Problem Selection . . . . . . . . . . . . . . . . . . . . . . . 48

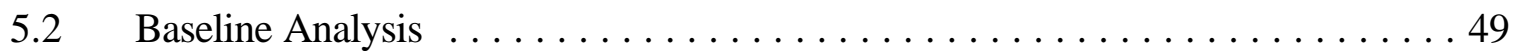

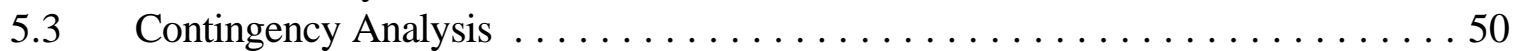

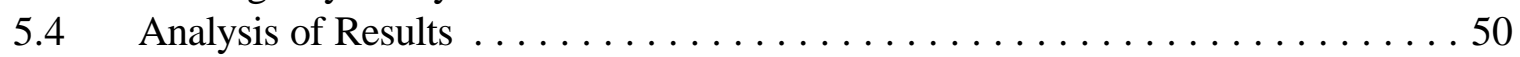

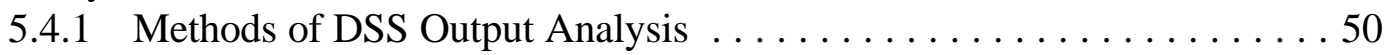

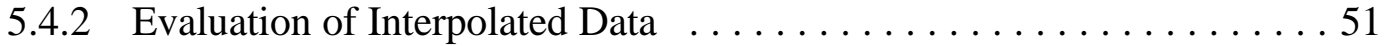

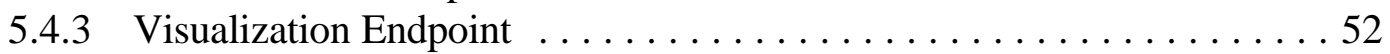

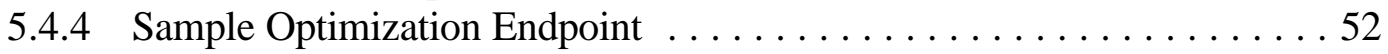

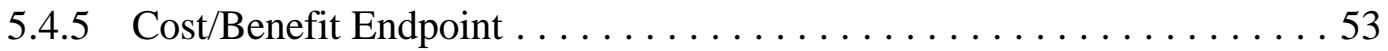

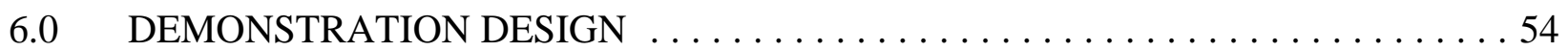

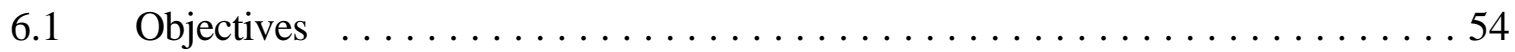

$6.2 \quad$ Experimental Design ............................... 54

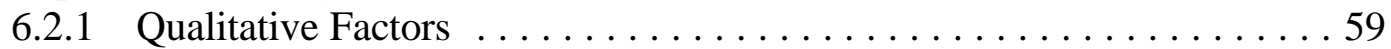

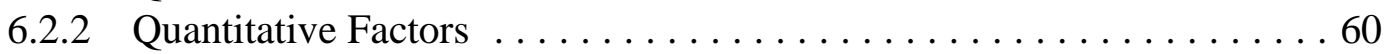

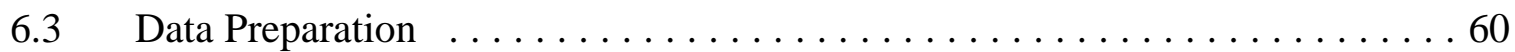

6.3.1 Pre-demonstration Test Problem . . . . . . . . . . . . . . . . . 61

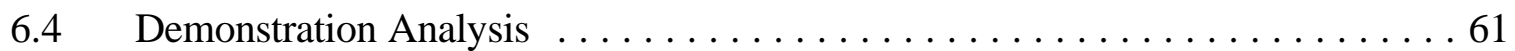

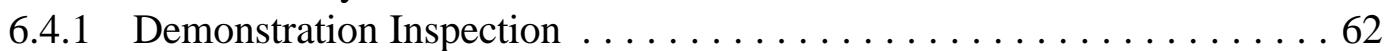

6.5 Demonstration Schedule .............................. 62

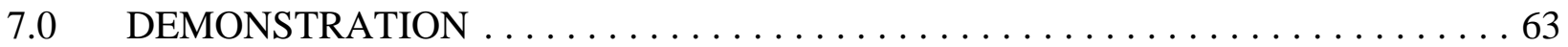

$7.1 \quad$ Communication and Documentation . . . . . . . . . . . . . . . . . . . 63

$7.2 \quad$ Data Presentation Procedures . . . . . . . . . . . . . . . . . . . 64

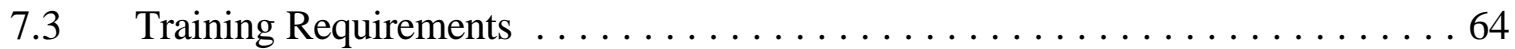

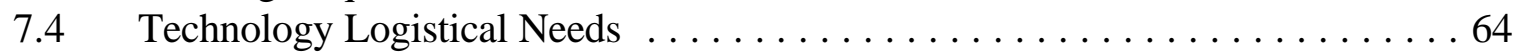

8.0 QUALITY ASSURANCE PROJECT PLAN (QAPP) $\ldots \ldots \ldots \ldots \ldots \ldots \ldots \ldots \ldots 66$

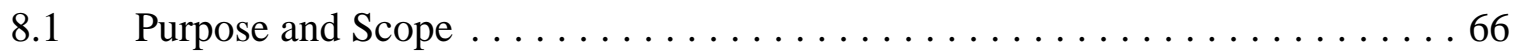

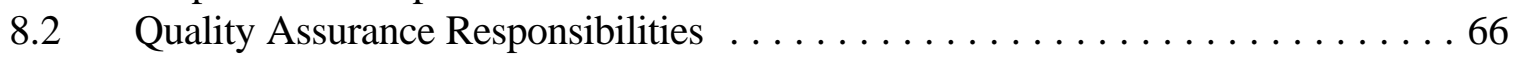

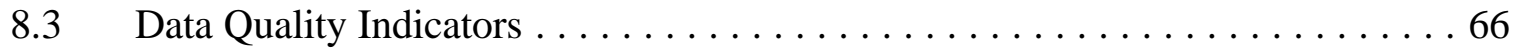

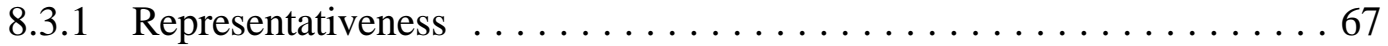

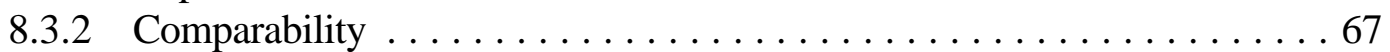

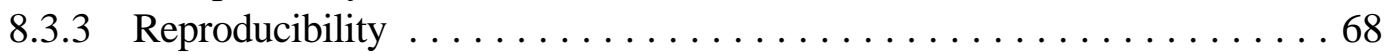

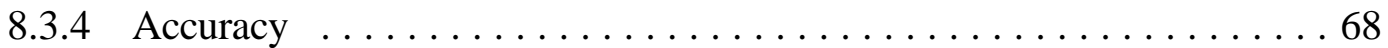

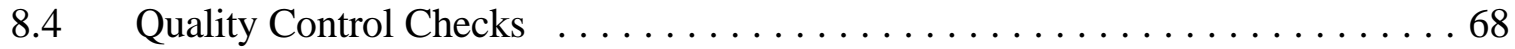

8.5 Data Reduction, Validation, and Reporting . . . . . . . . . . . . . . 69

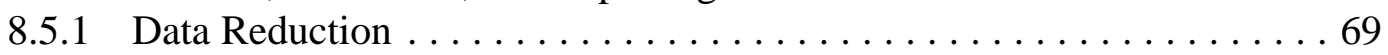

8.5.2 Data Validation . . . . . . . . . . . . . . . . . . . . . . . . 69

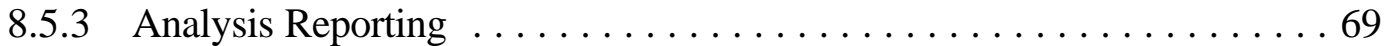

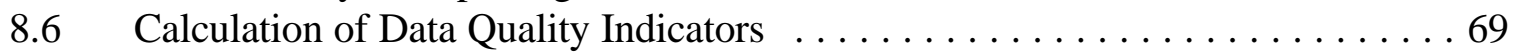

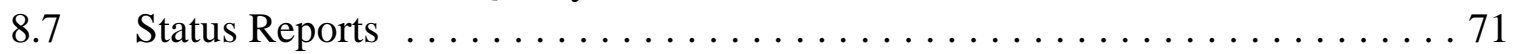

8.8 Demonstration Inspection Report $\ldots \ldots \ldots \ldots \ldots \ldots \ldots \ldots \ldots \ldots \ldots \ldots$ 
REFERENCES ........................................ 76

Appendix A: Contact Information for DSS Participants . . . . . . . . . . . . . . . . 77

Appendix B: $\quad$ DSS Demonstration Schedule . . . . . . . . . . . . . . . . . . . . . . . . . 79

\section{List of Tables}

Table $2.1 \quad$ DSS Demonstration Program Participants . . . . . . . . . . . . . . . 7

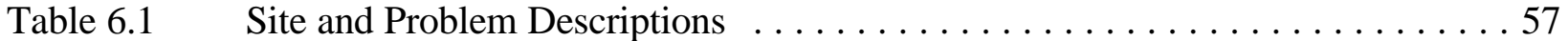

Table $6.2 \quad$ List of Data to be Supplied as Part of the Test Problems . . . . . . . . . . . 58

Table 9.1 Example of Information on the DSS System Used in the Analysis . . . . . . . 74

\section{List of Figures}

Figure $1 \quad$ DSS Technology Demonstration Organization Chart $\ldots \ldots \ldots \ldots \ldots$ 


\section{APPROVAL SIGNATURES}

This document is intended to ensure that all aspects of the demonstration are documented, scientifically sound, and that operational procedures are conducted within quality assurance/quality control specifications.

The signatures of the individuals below indicate concurrence with, and agreement to operate in compliance with the procedures specified in this document.

\section{U.S. Environmental Protection Agency}

Project Manager:

$$
\text { Eric Koglin }
$$

Date

\section{U.S. Department of Energy}

Project Officer:

$$
\text { Stan Morton }
$$

Date

\section{Brookhaven National Laboratory}

Technical Lead:

$$
\text { Terry Sullivan }
$$

Date

\section{Oak Ridge National Laboratory}

Program Manager:

$$
\text { Roger A. Jenkins }
$$

Date

Technical Lead:

$$
\text { Anthony Armstrong }
$$

\section{Date}

Quality Assurance:

$$
\text { Janet Wagner }
$$

\section{Date}




\section{DEVELOPERS APPROVAL SIGNATURES}

C-Tech: Environmental Visualization System (EVS)

Representative:

$$
\text { Reed Copsey }
$$

Date

Decision/FX:a) Sample FX, b) GroundwaterFX

Representative:

Bob Knowlton

Date

Environmental Software: SitePro

Representative:

Bern Baumgartner

Date

ESRI: ARCVIEW

Representative:

$$
\text { Jennifer Zoerkler }
$$

Date

University of Tennessee: SADA

Representative:

Robert Stewart

Date 


\section{ABBREVIATIONS AND ACRONYMS}

\begin{tabular}{|c|c|}
\hline bgs & below ground surface \\
\hline $\mathrm{BNL}$ & Brookhaven National Laboratory \\
\hline CSCT & Consortium for Site Characterization Technology \\
\hline DOE & U.S. Department of Energy \\
\hline DSS & Decision Support Software \\
\hline dxf & data exchange format \\
\hline EDB & Ethylene di-bromide \\
\hline EPA & U.S. Environmental Protection Agency \\
\hline ESD-LV & $\begin{array}{l}\text { U.S. Environmental Protection Agency's (EPA) Office of Research and Development, } \\
\text { National Exposure Research Laboratory, Environmental Sciences Division - Las } \\
\text { Vegas, Nevada }\end{array}$ \\
\hline ESRI & Environmental Systems Research Institute \\
\hline ETV & Environmental Technology Verification Program \\
\hline ETVR & Environmental Technology Verification Report \\
\hline EVS & Environmental Visualization System \\
\hline GIS & Geographical Information System \\
\hline GUI & Graphical User Interface \\
\hline ha & hectare \\
\hline MAE & Mean Average Error \\
\hline msl & mean sea level \\
\hline NAMP & DOE National Analytical Management Program \\
\hline NME & Negative Mean Error \\
\hline NMERI & New Mexico Engineering Research Institute \\
\hline ORNL & Oak Ridge National Laboratory \\
\hline ORO & Oak Ridge Operations \\
\hline PCB & Polychlorinated biphenyls \\
\hline PME & positive mean error \\
\hline ppm & parts per million \\
\hline ppb & parts per billion \\
\hline QA & Quality Assurance \\
\hline QAPP & Quality Assurance Project Plan \\
\hline QC & Quality Control \\
\hline RAGS & Risk Assessment Guidance for Superfund \\
\hline $\mathrm{RE} \%$ & relative error $\%$ \\
\hline RMSE & root mean square error \\
\hline SADA & Spatial Analysis Decision Assistance \\
\hline SITE & Superfund Innovative Technology Evaluation \\
\hline TCE & Trichlorethene \\
\hline TINs & Triangulated Irregular Networks \\
\hline VOC & Volatile Organic Compound \\
\hline
\end{tabular}




\subsection{INTRODUCTION}

The performance evaluation of innovative and alternative environmental technologies is an integral part of the U. S. Environmental Protection Agency's (EPA) mission. Early efforts focused on evaluating technologies that supported the implementation of the Clean Air and Clean Water Acts. In 1986 the Agency began to demonstrate and evaluate the cost and performance of remediation and monitoring technologies under the Superfund Innovative Technology Evaluation (SITE) program (in response to the mandate in the Superfund Amendments and Reauthorization Act of 1986 (SARA)). In 1990, the U.S. Technology Policy was announced. This policy placed a renewed emphasis on "...making the best use of technology in achieving the national goals of improved quality of life for all Americans, continued economic growth, and national security." In the spirit of the technology policy, the Agency began to direct a portion of its resources toward the promotion, recognition, acceptance, and use of U.S.-developed innovative environmental technologies both domestically and abroad.

The Environmental Technology Verification (ETV) Program was created by the Agency to facilitate the deployment of innovative technologies through performance verification and information dissemination. The goal of the ETV Program is to further environmental protection by substantially accelerating the acceptance and use of improved and cost-effective technologies. The ETV Program is intended to assist and inform those involved in the design, distribution, permitting, and purchase of environmental technologies. The ETV Program capitalizes upon and applies the lessons that were learned in the implementation of the SITE Program to the verification of 12 categories of environmental technology: Drinking Water Systems, Pollution Prevention/Waste Treatment, Pollution Prevention/ Innovative Coatings and Coatings Equipment, Air Pollution Control, Indoor Air Products, Advanced Monitoring Systems, EvTEC (an independent, private-sector approach), Wet Weather Flows Technologies, Pollution Prevention/Metal Finishing, Source Water Protection Technologies, Site Characterization and Monitoring Technology (a.k.a. Consortium for Site Characterization Technology (CSCT)), and Climate Change Technologies. For each pilot, EPA utilizes the expertise of partner "verification organizations" to design efficient procedures for conducting performance tests of environmental technologies. EPA selects its partners from both the public and private sectors including federal laboratories, states, universities, and private sector entities. Verification organizations oversee and report verification activities based on testing and quality assurance protocols developed with input from all major stakeholder/customer groups associated with the technology area.

September 14 - 25, 1998 the Site Characterization and Monitoring Technology Pilot, in cooperation with the U.S. Department of Energy's Environmental Management Program, will conduct a demonstration to verify the performance of six Decision Support Software packages.

\subsection{Decision Support Software Demonstration}

Decision Support Software (DSS) packages integrate environmental data and simulation models into a framework for making site characterization, monitoring, and cleanup decisions (e.g., where to sample, cost/benefit analysis of additional or reduced sampling, human and ecological risk analysis as a function of cleanup level, etc.). An effective DSS package should integrate, analyze, and 
present environmental information to assist a project manager in developing a cost-effective, defensible, cleanup/monitoring strategy.

DSS packages are new, innovative technologies that have not seen widespread use in the environmental field. However, they show promise as a means to facilitate understanding of contaminant behavior and help make cost-effective decisions about environmental issues. The rapid growth in computing power over the past ten years has permitted development of powerful software systems that operate on personal computers. The combination of an integrated approach and the potential to have these tools on a personal computer is attractive to many environmental managers. For this reason, the EPA Regions, several EPA Program Offices, and other Federal Agencies have expressed interest in the performance and potential applications of environmental DSS programs when tested under real-world situations.

The preceding description of Decision Support Software defines the characteristics of DSS, but not the components. As such, the definition is vague and a wide range of software can be considered as DSS. This makes the demonstration unique and challenging. To limit the scope which will be addressed in this demonstration, three endpoints have been selected for evaluation: a) Visualization, b) Sample Optimization, and c) Cost/Benefit Analysis. The definitions for these three areas in this program follow.

Visualization: Visualization software will be evaluated in terms of the ability to integrate site and contamination data in a coherent and accurate fashion which aids in understanding the contamination problem. Tools used in visualization can range from data display in graphical or contour form to integrating site maps and aerial photos into the results.

Sample Optimization: Sample optimization software will be evaluated for soil and groundwater contamination problems in terms of predicting the minimum number and location of samples needed to define a contaminated region with a specified level of confidence.

Cost/Benefit Analysis: Cost/Benefit analysis software will be evaluated on soil and groundwater contamination problems. In general, cost/benefit analysis will be defined as the cost optimization relative to a benefit. There are many potential "benefits" that could be used for the analysis. For example, the benefit could be defined as a) changes in the size of remediation zones as a function of the degree of certainty in the decision for a fixed cleanup limit, b) changes in the size of the remediation area as a function of cleanup limits for a fixed degree of certainty in the decision, c) the probability of success in meeting cleanup criteria, or d) the reduction in human health risks as a function of the amount of remediation. The test problems will be discussed in detail in Section 4 and 6.

Based on visualization, sample optimization, and cost/benefit analysis, DSS packages will participate in a demonstration to provide information to assist in the evaluation of the performance of the DSS packages. It is important to emphasize that the software tested in the demonstration does not need to address all three endpoints to participate. Software will be evaluated only on the portions of the problem to which it is applied. Upon completion of the demonstration and evaluation of the results, EPA-ETV will issue a verification report for each DSS package. 
This section provides an overview of the demonstration plan. Five major topics are covered in this chapter: i) the objectives of the demonstration, ii) the elements of the demonstration plan, iii) an overview of the Site Characterization and Monitoring Technology Pilot, iv) an overview of the technology verification process, and v) the purpose of this demonstration plan.

\subsection{Demonstration Objectives}

In conventional approaches to environmental decision making, each of the processes is performed individually (e.g., fate and transport, risk analysis, cost/benefit, etc.) and often not in an internally consistent manner. In addition, because the conventional approach is performed on a piecemeal basis, it does not permit an easy evaluation of alternative scenarios or remedial approaches. This leads to inefficiencies and higher expenses. Environmental DSS remedy this problem by incorporating several models to perform an integrated assessment.

The objectives of the program are to provide thorough testing of the DSS products over a wide range of environmental conditions taken from real sites. The testing will permit an unbiased evaluation of the capabilities of the DSS to address real world problems.

\subsection{Elements of the Demonstration Plan}

This plan defines the following elements of the demonstration:

- $\quad$ Roles and responsibilities of demonstration participants.

- $\quad$ Procedures governing demonstration activities, such as data collection, to define test problems, data preparation, analysis, and interpretation.

- $\quad$ Experimental design of the demonstration.

- $\quad$ Quality assurance (QA) and quality control (QC) procedures for conducting the demonstration and for assessing the quality of the information generated from the demonstration.

\subsection{The Site Characterization and Monitoring Technology Pilot}

The Pilot is a partnership between the EPA and the Department of Energy (DOE). DOE has established programs and facilities (testing venues) for testing, demonstrating, and evaluating the performance of monitoring, measurement and site characterization technologies, among other technologies. As a partnership, the Pilot offers valuable technical expertise to support the demonstration and verification of the performance of new and emerging technologies and offers access to a wide array of testing venues.

A goal of the Pilot is to facilitate the acceptance and use of cost-effective technologies applicable to a wide range of environmental problems. The Pilot meets this goal by working with technology developers and other agencies in planning and conducting demonstrations, evaluating data generated in demonstrations, and managing and disseminating information. The Pilot does not offer any financial support to those desiring to conduct a technology demonstration. The developer is expected to secure the appropriate resources to support their part of the technology verification process. 


\subsubsection{Technology Verification Process}

The technology verification process is intended to serve as a template for conducting technology demonstrations that will generate high-quality data which EPA can use to verify technology performance. Four key steps are inherent in the process.

- $\quad$ Needs identification and technology selection.

- Demonstration planning and implementation.

- $\quad$ Report preparation.

- Information distribution.

Needs Identification and Technology Selection: The first aspect of the technology verification process is to determine technology needs of the EPA and the regulated community. The EPA, U.S. Department of Energy, U.S. Department of Defense, industry, and state agencies are asked to identify technology needs and interest in a technology. Once a technology need is established, a search is conducted to identify suitable technologies that will address the need. The technology search and identification process consists of reviewing responses to Commerce Business Daily announcements, searches of industry and trade publications, attendance at related conferences, and leads from technology developers. Characterization and monitoring technologies are evaluated against the following criteria:

- $\quad$ Meets user needs.

- $\quad$ May be used in the field or in a mobile laboratory.

- $\quad$ Applicable to a variety of environmentally impacted sites.

- High potential for resolving problems for which current methods are unsatisfactory.

- $\quad$ Costs are competitive with current methods.

- $\quad$ Performance is better than current methods in areas such as data quality, sample preparation, or analytical turnaround time.

- Uses techniques that are easier and safer than current methods.

- Is a commercially available, field-ready technology.

Demonstration Planning and Implementation: After a technology has been selected, EPA, the verification organization, and the developer agree to responsibilities for conducting the demonstration and evaluating the technology. The following issues are addressed at this time:

- Identifying demonstration sites that will provide the appropriate physical or chemical attributes, in the desired environmental media.

- Identifying and defining the roles of demonstration participants, observers, and reviewers.

- $\quad$ Determining logistical and support requirements (for example, field equipment, power and water sources, mobile laboratory, communications network).

- $\quad$ Arranging analytical and sampling support.

- $\quad$ Preparing and implementing a demonstration plan that addresses the experimental design, sampling design, quality assurance/quality control (QA/QC), health and safety considerations, scheduling of field and laboratory operations, data analysis procedures, and reporting requirements. 
Report Preparation: Innovative technologies are evaluated independently and, when possible, against conventional technologies. The field technologies are operated by the developers in the presence of independent technology observers. The technology observers are provided by EPA or a third party group. Demonstration data are used to evaluate the capabilities, limitations, and field applications of each technology. Following the demonstration, all raw and reduced data used to evaluate each technology are compiled into an Environmental Technology Verification Report (ETVR), which is mandated by EPA as a record of the demonstration. A data summary and detailed evaluation of each technology are published in an ETVR.

Information Distribution: The goal of the information distribution strategy is to ensure that ETVRs are readily available to interested parties through traditional data distribution pathways, such as printed documents. Documents are also available on the World Wide Web through the ETV Web site (http://www.epa.gov/etv) and through a Web site supported by the EPA Office of Solid Waste and Emergency Response's Technology Innovation Office (http://CLU-in.com).

\subsection{Purpose of this Demonstration Plan}

The purpose of the demonstration plan is to describe the procedures that will be applied to generate the data and information that can be used to verify the performance goals of six Decision Support Software packages. This document incorporates the QA/QC elements needed to provide test problems of appropriate quality sufficient to reach a defensible position regarding technology performance. This is not a method validation study, nor will it represent every environmental situation which may be acceptable for this technology. But it will provide data of sufficient quality to make a judgement about the application of the technology under conditions similar to those encountered in the field. 


\subsection{DEMONSTRATION RESPONSIBILITIES AND COMMUNICATION}

This section identifies the organizations involved in this demonstration and describes the primary responsibilities of each organization. It also describes the methods and frequency of communication that will be used in coordinating the demonstration activities.

\subsection{Demonstration Organization and Participants}

This demonstration is being conducted by the DSS Developer or assigned representative with support by Brookhaven National Laboratory (BNL) and Oak Ridge National Laboratory (ORNL) under the direction of the U.S. Environmental Protection Agency's (EPA) Office of Research and Development, National Exposure Research Laboratory, Environmental Sciences Division - Las Vegas, Nevada (CRD-LV) and the Department of Energy's National Analytical Management Program, (NAMP) Idaho Falls, Idaho. The CRD-LV's role is to administer the CSCT Demonstration Program with the assistance of the NAMP. BNL's and ORNL's role is to provide technical and administrative leadership and support while conducting the demonstration.

Participants in this demonstration are listed in Table 2.1. Detailed information on how to contact the participants is provided in Appendix A. The specific responsibilities of each demonstration participant are discussed in Section 2.3.

Based on the three endpoints presented in Section 1.0 of this report, the software products SitePro and ARCVIEW will demonstrate their capabilities for the Visualization endpoint. The software products EVS, Sampling $F X$, Groundwater $F X$, and SADA will demonstrate their capabilities on all three endpoints, Visualization, Sample Optimization, and Cost/Benefit analysis.

\subsection{Organization}

An organization chart presenting the relationship between the different participants is displayed in Figure 1. The roles and responsibilities of each participant are discussed in Section 2.3.

\subsection{Responsibilities}

Representatives from BNL and ORNL (Terry Sullivan and Anthony Armstrong), in consultation with DSS Developers and the EPA project manager, Eric Koglin, are responsible for the following elements of this demonstration:

- $\quad$ Designing and preparing all elements of the demonstration plan.

- Developing a Quality Assurance Project Plan (QAPP). The nature of this demonstration prevents the use of typical quality assurance procedures. Section 8 of this report will discuss how the principles of Quality Assurance will be applied. 
Table 2.1 DSS Demonstration Program Participants

\begin{tabular}{|c|c|c|c|}
\hline Name & Affiliation & Role & DSS Product \\
\hline Eric Koglin & EPA - ESD-LV & EPA Project Manager & N/A \\
\hline Stan Morton & DOE-NAMP & DOE Project Manager & N/A \\
\hline Gary Hartman & DOE-ORO & $\begin{array}{l}\text { DOE Project } \\
\text { Management }\end{array}$ & N/A \\
\hline Terry Sullivan & $\mathrm{BNL}$ & $\begin{array}{l}\text { Technical and } \\
\text { Administrative Lead }\end{array}$ & N/A \\
\hline Anthony Armstrong & ORNL & $\begin{array}{l}\text { Technical and } \\
\text { Administrative Lead }\end{array}$ & N/A \\
\hline Amy Dindal & ORNL & $\begin{array}{l}\text { Technical and } \\
\text { Administrative } \\
\text { Support }\end{array}$ & N/A \\
\hline Roger Jenkins & ORNL & $\begin{array}{l}\text { Technical and } \\
\text { Administrative } \\
\text { Support }\end{array}$ & N/A \\
\hline Dennis Morrison & $\begin{array}{l}\text { New Mexico } \\
\text { Engineering Research } \\
\text { Institute }\end{array}$ & $\begin{array}{l}\text { Demonstration Site } \\
\text { Support }\end{array}$ & N/A \\
\hline Bern Baumgartner & $\begin{array}{l}\text { Environmental } \\
\text { Software }\end{array}$ & Developer & SitePro \\
\hline Reed Copsey & C-Tech & Developer & $\begin{array}{l}\text { Environmental } \\
\text { Visualization } \\
\text { System (EVS) }\end{array}$ \\
\hline Bob Knowlton & Decision/FX & Developer & $\begin{array}{l}\text { a) Sampling } F X \\
\text { b) Groundwater } F X\end{array}$ \\
\hline Robert Stewart & $\begin{array}{l}\text { University of } \\
\text { Tennessee }\end{array}$ & Developer & SADA \\
\hline Jennifer Zoerkler & ESRI & Developer & ARCVIEW \\
\hline
\end{tabular}




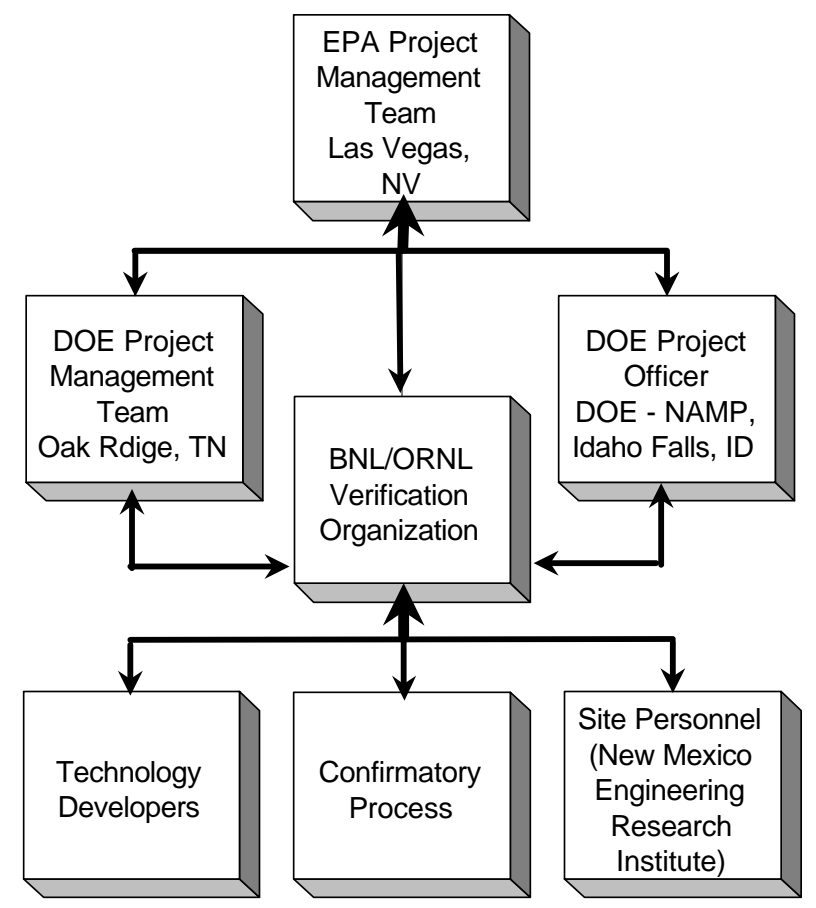

Refer to Table 1 for the names of specific individuals involved in demonstration

- $\quad$ Providing needed logistical support, establishing a communication network, and scheduling and coordinating the activities of all demonstration participants.

- Ensuring that appropriate sites and data sets are selected consistently with the objectives of the demonstration.

- $\quad$ Acquiring the necessary environmental data sets for analysis.

- $\quad$ Preparing the test problems for the demonstration.

- Analyzing the test problems prior to the demonstration as a basis for evaluation of the DSS.

- Managing, evaluating, interpreting, and reporting on the analyses generated by the demonstration.

- $\quad$ Evaluating and reporting on the performance of the DSS technologies.

The Developers are responsible for providing the following elements of the demonstration:

- Detailed procedures for using the technology. This could be the documentation for use of the DSS and discussions of available training courses. As part of the evaluation report, each Developer will be asked to supply a narrative description of their software describing the major process models incorporated into their code and a description of how these process models are implemented in the code.

- Complete, market-ready technology for demonstration. Developers will not be allowed to modify the software during the demonstration.

- $\quad$ Data requirements to successfully operate the DSS. 
- $\quad$ Operation of the DSS technology during the demonstration.

- Documentation of the DSS methodology.

- Analysis of output files to support the evaluation of the technology against the baseline.

- $\quad$ Data reduction and interpretation support, as required to support the decision.

- $\quad$ Logistical, and other support, as required.

The demonstration site host, NMERI, and the EPA will provide the following support:

- $\quad$ Site access.

- Other logistical information and support needed to coordinate access to the site for the demonstration. 


\subsection{TECHNOLOGY DESCRIPTION}

The genesis of environmental Decision Support Software (DSS) begins in the late 1980's and coincides with two events: a) increased awareness of the complexity of environmental contamination issues which precipitated increased site characterization and data collection, and b) rapid increases in computational power which provided a means of storing, handling, and analyzing the large amounts of data generated in defining contamination issues. Addressing the complexity of many environmental problems required expertise in several fields including but not limited to hydrogeology, geochemistry, statistics (geostatistics), human health risk assessment, economics (cost estimation), and contaminant transport. The DSS concept was presented to environmental decision makers as a tool that would integrate many of these areas into a consistent package for supporting decisions. This shift in emphasis from obtaining a technical parameter (e.g., concentration, cost, risk, etc.) to supporting a decision lead naturally to an integrated analysis.

In the early 1990's, environmental DSS programs, which integrated site data and provided visualization tools became available. These tools were originally developed for UNIX-based computer operating systems which required a WorkStation and expertise in UNIX. This impacted their availability for wide-scale use. Simultaneously, data analysis tools such as flow and transport models, geostatistical data analysis models, and cost/benefit assessment models were incorporated into some DSS programs. As computer technology improved, many of these systems were modified to operate on Windows-based systems and thereby, became available for wide-spread use.

In addition to an integrated analysis, many DSS possess the ability to address uncertainty that occurs due to incomplete knowledge about the system and the natural variability present in the data. The statistically based analysis assists the decision maker by incorporating the effects of uncertainty in the decision process.

This demonstration will evaluate different software tools. The following sections describe each of these software tools including the scientific principles, components and application history of the technology. The performance range through which the technology is applicable, as well as the advantages and limitations of the technology are also included. This section concludes with the technology performance goals. These goals will be used to evaluate the software in terms specific to the demonstration as well as terms relevant to general applications.

\subsection{Technology Overview}

Six different software packages will be evaluated as part of the Decision Support Software demonstration. The following sections, which have been provided by the DSS Developers, present background information on each of these computer codes. The background information includes the primary application, hardware, cost and training requirements. Advantages of these technologies over conventional approaches are also discussed. 


\subsubsection{Environmental Systems Research Institute (ESRI)}

\subsubsection{Primary Application}

A geographic information system (GIS) is a computer-based tool for mapping and analyzing things that exist and events that happen on earth. GIS technology integrates common database operations such as query and statistical analysis with the unique visualization and geographic analysis benefits offered by maps. These abilities distinguish GIS from other information systems and make it valuable to a wide range of public and private enterprises for explaining events, predicting outcomes, and planning strategies.

As part of the Visualization endpoint for the Environmental Technology Verification Program, ESRI software will demonstrate database connectivity, geographic display and mapping functionality, and model interfaces, which are vital tools to site characterization, risk assessment, and groundwater remediation. These tools will also provide the inputs for 3-D modeling of contaminant plumes, and the decision support criteria for placement of injection/extraction wells.

\section{Supported Platforms:}

$\begin{array}{ll}\text { Platform } & \text { Operating System } \\ \text { Windows PC * } & \text { MS-DOS 5.0 or later, and } \\ & \text { Microsoft Windows NT } \\ & 3.5 .1 \text { or higher, Windows } \\ & 95 / 98 \\ \text { Digital UNIX Alpha } & \text { Digital UNIX v4.0b }\end{array}$

HP 9000/700 \& $8 \times 7^{\text {** }}$

IBM RS/6000

Silicon Graphics

Solaris 2

\section{AIX 4.1.5.0 (RTE -} supplied by ESRI)

IRIX Rev. 6.2, with these patches: SG0001717, SG0002086, SG0002161, SG0002044, 6.2_POSIX patch

Solaris 2.5.1, with these patches for Open GL/3D Analyst:

103796-12 (FFB patch), 103566-18 (Xsun jumbo patch)

\begin{tabular}{|c|c|c|c|}
\hline $\begin{array}{l}\text { Video graphics } \\
\text { adapter (VGA) or } \\
\text { better resolution } \\
\text { monitor }\end{array}$ & $\begin{array}{l}\text { Minimum } \\
\text { Memory } \\
12 \mathrm{MB} \\
\text { (16 MB } \\
\text { recommended) }\end{array}$ & $\begin{array}{l}\text { Swap } \\
\text { Space }\end{array}$ & Databases \\
\hline Motif or $C D E$ & $\begin{array}{l}64 M B \text { (based } \\
\text { on a single } \\
\text { user) }\end{array}$ & $\begin{array}{l}75 \mathrm{MB} \\
\text { (based on } \\
\text { a single } \\
\text { user) }\end{array}$ & $\begin{array}{l}\text { Informix-OnLine Dynamic } \\
\text { Server: } 7.20 . U C 3 \\
\text { CA-OpenIngres: } 1.2 / 01 \\
\text { Oracle: Oracle7 Server } \\
\text { 7.3.3 } \\
\text { Sybase: SQL Server } \\
11.0 .2\end{array}$ \\
\hline CDE or HP VUE & $\begin{array}{l}32 M B \text { (based } \\
\text { on a single } \\
\text { user) }\end{array}$ & $\begin{array}{l}100 \mathrm{MB} \\
\text { (based on } \\
\text { a single } \\
\text { user) }\end{array}$ & $\begin{array}{l}\text { Informix-OnLine Dynamic } \\
\text { Server: } 7.20 . U C 2 \\
\text { CA-OpenIngres: } 1.2 \\
\text { Oracle: Oracle7 Server } \\
\text { 7.3.3 } \\
\text { Sybase: SQL Server } \\
11.0 .2\end{array}$ \\
\hline $\begin{array}{l}\text { CDE or AIX } \\
\text { Windows Rev. } \\
4.1 .50\end{array}$ & $\begin{array}{l}32 M B \text { (based } \\
\text { on a single } \\
\text { user) }\end{array}$ & $\begin{array}{l}64 M B \\
\text { (based on } \\
\text { a single } \\
\text { user) }\end{array}$ & $\begin{array}{l}\text { Informix-OnLine Dynamic } \\
\text { Server: } 7.20 . U C 2 \\
\text { CA-OpenIngres: } 1.2 \\
\text { Oracle: Oracle7 Server } \\
\text { 7.3.3 } \\
\text { Sybase: SQL Server } \\
11.0 .2\end{array}$ \\
\hline $\begin{array}{l}\text { Version } 6.2 \text { based } \\
\text { on OSF/Motif } 1.2 .4\end{array}$ & $\begin{array}{l}64 M B \text { (based } \\
\text { on a single } \\
\text { user) }\end{array}$ & $\begin{array}{l}100 \mathrm{MB} \\
\text { (based on } \\
\text { a single } \\
\text { user) }\end{array}$ & $\begin{array}{l}\text { Informix-OnLine Dynamic } \\
\text { Server: } 7.20 . U C 2 \\
\text { CA-OpenIngres: Not } \\
\text { Applicable } \\
\text { Oracle: Oracle7 Server } \\
7.3 .3 \\
\text { Sybase: SQL Server } \\
11.0 .2\end{array}$ \\
\hline $\begin{array}{l}\text { CDE or } \\
\text { OpenWindows }\end{array}$ & $\begin{array}{l}32 M B \text { (based } \\
\text { on a single } \\
\text { user) }\end{array}$ & $\begin{array}{l}100 \mathrm{MB} \\
\text { (based on } \\
\text { a single } \\
\text { user) }\end{array}$ & $\begin{array}{l}\text { Informix-OnLine Dynamic } \\
\text { Server: } 7.20 . U C 2 \\
\text { CA-OpenIngres: } 1.2 \\
\text { Oracle: Oracle7 Server } \\
\text { 7.3.3 } \\
\text { Sybase: SQL Server } \\
11.0 .2\end{array}$ \\
\hline
\end{tabular}


${ }^{*}$ An industry-standard personal computer with at least an 80486 or higher Intel-based microprocessor, and a hard disk

${ }^{* *}$ Filesystem: Must be configured for long filenames

\subsection{Key Applications}

- $\quad$ Site characterization and remediation.

- $\quad$ Risk Assessment.

- $\quad$ Environmental monitoring and modeling.

\subsection{Data Used}

- $\quad$ Environmental/Facility Site Data.

- $\quad$ Aerial Photo and Satellite Imagery.

- $\quad$ Toxic Site Location Data.

- Natural Resource Data.

- Well and Borelog Data.

- $\quad$ Project Impact Data.

\subsection{Cost of the Technology}

Pricing varies for single stand-alone systems through enterprise-wide systems. ESRI software is available for purchase from ESRI or through authorized resellers. Several existing contracts also make purchasing software easy for the federal government, including the ESRI GSA Schedule \#GS35F-5086H. ESRI representatives assist customers in choosing the appropriate system configuration for their needs.

\subsection{Training Requirements and User Support}

Training is the process of teaching "how-to-use" the software, while education is the broaderbased transfer of knowledge including concepts of cartography, spatial analysis, database management, and so forth. Only through appropriate education can users successfully implement and use GIS technology. ESRI offers training courses in the use of its software products. Classes are offered at the ESRI headquarters in Redlands, CA, at the regional offices, and by ESRI Authorized Instructors. A "Virtual Campus" also offers access to training classes over the internet, at the user's own pace and convenience.

ESRI also provides a "hot-line technical support" number for the purpose of providing user assistance and guidance in the implementation of the software during the period of time which the product is covered under its original warranty. ArcView and its optional extensions have a 60-day complimentary period for technical support. Additional technical support services are available from ESRI through software maintenance and support programs.

\subsection{Licensing Requirements}


ArcView and its optional extensions are licensed as shrink-wrapped products. A license may reside on a stand-alone workstation or PC, or on a network. However, one license must be purchased for every concurrent user of the ArcView software and its optional extensions.

\subsubsection{History of ESRI}

ESRI was founded in 1969 by Jack and Laura Dangermond as a privately held consulting group. During the 1970's, ESRI focused on the development of fundamental ideas of GIS and their application in real-world projects such as developing a plan for rebuilding the City of Baltimore, Maryland, and helping Mobil Oil select a site for the new town of Reston, Virginia.

In its second decade, ESRI moved from a company primarily concerned with carrying out projects to a company building software tools and products. Dangermond realized that to leverage the methods and technologies developed for project work during the 1970s, the company needed to develop commercial software products that others could use and rely on for doing their own projects. The company hired several software engineers and created its first software product.

ArcView GIS, as a member of the ESRI product family, reflects ESRI's more than 25 years of experience in providing high-quality GIS software and related services. ESRI's flagship product ARC/INFO is recognized as the most advanced GIS software worldwide. ESRI software serves a diverse set of application needs in federal, state, and local government, oil and gas, forestry, transportation, university, utility, private industry and many other application areas. With more than 100,000 copies in use worldwide, ArcView GIS helps thousands of organizations to understand relationships, make better decisions, and solve problems faster.

GIS is poised for ever greater growth during the rest of the decade and beyond. Innovations in computer technology now allow sophisticated GIS operations to be performed on the desktop. Faster and cheaper computers, network processing, electronic data publishing, and improved easierto-use GIS technologies are fueling rapid growth in the desktop area. Private businesses are adopting GIS technology as a decision support tool. And with the introduction of live mapping applications to the World Wide Web, anyone with a computer has access to the benefits of GIS technology.

Technology Applications

\author{
Site Characterization \& Remediation \\ Impact Assessment \\ Site Investigation \\ Well Log and Data Management \\ Fate and Transport Modeling \\ Plume Modeling \\ Remedial Investigation \\ Groundwater Sample Management \\ Waste Disposal Site Location
}

Environmental Modeling

Fate and Transport Modeling

\author{
Waste Management \\ Chemical Hazards Management \\ Storage Tank Management \\ Inspection Prioritization \\ Materials Tracking \\ HazMat Transportation Routing \\ Landfill and Waste Site Selection
}

\author{
Environmental Monitoring \\ Water Quality
}


Groundwater Contaminant Modeling

Particle Tracking

Watershed Modeling

Hydrologic Flow Analysis

Saltwater Intrusion Modeling

Air Dispersion Modeling
Groundwater Pollution

Soil Gas Measurements

Radon Measurements

Radiation Detection

Indoor Air Pollution

\subsubsection{ARCVIEW Advantages and Operating Parameters}

ArcView

ArcView takes desktop users beyond the basic limitations of "desktop mapping" and offers the only comprehensive Out-of-the-Box Desktop GIS in the industry. Users are able to produce tailored products by analyzing data layers to determine patterns, relationships and trends. Customization is possible using the ArcView program language, Avenue.

ArcView GIS links traditional data analysis tools, such as spreadsheets and business graphics, with maps for a completely integrated analysis system. ArcView GIS can be used as a stand-alone project system or extended into an entire department, division, or organization. ArcView GIS may be used to access and view the thousands of ARC/INFO databases in existence, including PC ARC/INFO and SDE data. ArcView can also directly use raster image data in a wide variety of formats. Users can access and visualize geographic data stored either locally or remotely over a network.

The extensible software architecture of ArcView GIS delivers a scaleable platform for GIS computing. This new architecture has enabled ESRI to develop a series of "plug-in" modules for ArcView GIS that can be mixed and matched to dramatically extend its functional capabilities, taking desktop GIS to an entirely new level.

Spatial Analyst - An Extension to ArcView

ArcView Spatial Analyst introduces a broad range of powerful new spatial modeling and analysis features previously not available to desktop users. This new extension allows a user to create, query, map, and analyze cell-based raster data and to perform integrated raster-vector analysis.

Unique to ArcView Spatial Analyst is the ability not only to work with raster-based data (including the ability to overlay, query, and display multiple raster themes), but also to perform integrated raster-vector theme analysis. This analysis would include a task such as aggregating properties of a raster theme based on an overlaid vector theme.

ArcView Spatial Analyst is particularly well suited for providing solutions to problems that require distance or other continuous surface modeling information to be considered as part of the analysis. For example, site suitability analysis often requires combining information about slope (information best represented as raster data) and the location of roads and property boundaries (information best represented as vector data) in order to arrive at the best location for a new facility. Spatial Analyst not only can generate the appropriate surface representation of information from a 
variety of existing data sources, but it can also derive new information from the overlay of multiple theme types. The results are then used to suggest possible solutions to the original problem.

ArcView Spatial Analyst can create a raster data source from any point, line, or polygon feature source or import data from standard formats including TIFF, BIL, SUN raster, USGS DEM, DTED, and others.

In addition, ArcView Spatial Analyst includes a suite of more advanced raster analysis tools that can be accessed through Avenue software requests. Avenue is ArcView GIS software's built-in application development language. ArcView Spatial Analyst combined with Avenue can provide you with hydrologic, cost, distance, and visibility tools on the desktop. Developers are able to deliver highly sophisticated spatial analysis applications based on these extended capabilities. ArcView Spatial Analyst is available for Windows and UNIX and requires the base ArcView GIS Version 3.X software.

\section{3-D Analyst - An Extension to ArcView}

The 3D Analyst allows for the viewing and analysis of 3D data in a new ArcView Document type called a Scene. The 3D Analyst provides functionality to assist users with three primary tasks surface model construction, analysis, and display.

The 3D Analyst supports the creation of Triangulated Irregular Networks (TINs) from feature themes in a view. TINs are vector based, topologically structured models that have desirable characteristics for representing terrain and other surfaces. Selected records from active themes will be used as input. This methodology enables the user to visualize, via the view display, what will be used to create a TIN before processing begins.

Existing TINs can be modified by adding features to them. Individual nodes in a TIN can have their $\mathrm{z}$ values modified. Nodes can also be moved or deleted. This incremental refinement will help users create high quality surfaces. The capability to edit is also important when changes to a surface in the real world (new roads, buildings, reservoirs, etc.) need to be reflected in an existing model without re-creating it from scratch.

The 3D Analyst goes beyond common forms of surface analysis, such as contouring and slope/aspect derivation, by providing attribute support, low-level navigation tools, and iterators for TINs. Numeric values representing user defined attributes can be assigned to triangle nodes (point features) and facets (areal features). Thus, for any location on a TIN the user can access not only the surface geometry but other thematic characteristics such as landcover. The navigation tools and iterators are useful to applications that need to walk through the triangulation or run through a collection of triangles that satisfy some criterion. An example iterator is one that will return all triangles that contribute flow to a point location. These capabilities should be of significant benefit to application Developers.

\subsubsection{Environmental Visualization System}


C Tech's Environmental Visualization System (EVS) software runs on virtually any PC running Windows 95 or Windows NT Workstation. EVS unites state-of-the art analysis and visualization tools into a software system developed to meet the needs of geologists, geochemists, engineers and modelers. EVS's graphical user interface is integrated with modular analysis and graphics routines. These can be customized and combined to satisfy the analysis and visualization needs of any application. EVS's tools will reduce site assessment costs and enhance the capability to analyze and present data for assessments, remediation planning, litigation support, regulatory reporting, and public relations. Options include PRO version with animation creation and advanced features; classroom and on-site training; and ground water and solute transport modeling.

\subsubsection{1 $\quad$ EVS Hardware System Requirements}

EVS has very few specific hardware requirements, and has been designed to run on a wide range of PC hardware. The following table gives recommendations for system configurations. Of these requirements, memory and CPU speed have the greatest impact on calculation time, while graphics resolution and number of displayable colors affect the appearance on screen. All system hardware must be Windows 95 or Windows NT compatible. 


\begin{tabular}{|c|c|c|c|}
\hline Hardware Item & Demo Minimum & $\begin{array}{l}\text { Installation } \\
\text { Minimum }\end{array}$ & Ideal Configuration \\
\hline CPU & Pentium 60 & Pentium 120 & Pentium II 400 \\
\hline$\overline{\text { RAM }}$ & $48 \mathrm{Mb}$ & $\begin{array}{l}64 \mathrm{Mb}(128 \mathrm{Mb} \\
\text { recommended) }\end{array}$ & $256 \mathrm{Mb}$ (or more) \\
\hline Hard Disk & $\begin{array}{l}120 \mathrm{Mb} \text { swap } \\
85 \mathrm{Mb} \text { installation } \\
300 \mathrm{Mb} \text { free }\end{array}$ & $\begin{array}{l}200 \mathrm{Mb} \text { swap } \\
85 \mathrm{Mb} \text { installation } \\
500 \mathrm{Mb} \text { free }\end{array}$ & $\begin{array}{l}400-800 \mathrm{Mb} \text { swap } \\
85 \mathrm{Mb} \text { installation } \\
1 \mathrm{~Gb} \text { free }\end{array}$ \\
\hline Graphics Card & $\begin{array}{l}1024 \times 768 \\
64 \mathrm{k} \text { colors }\end{array}$ & $\begin{array}{l}1024 \times 768 \\
64 \mathrm{k} \text { colors }\end{array}$ & $\begin{array}{l}1280 \times 1024 \text { or } 1600 \times 1200 \\
16 \text { million colors }\end{array}$ \\
\hline Floppy drive & 3.5" high density & 3.5" high density & 3.5" high density \\
\hline Monitor & 15 inch color & 17 inch color & 20 to 21 inch color \\
\hline CD ROM Drive & Required & Required & Required \\
\hline $\begin{array}{l}\text { e-mail, web \& ftp } \\
\text { access }\end{array}$ & Recommended & Recommended & Required \\
\hline
\end{tabular}

\subsection{EVS Software Interfaces}

EVS does not require any additional software and it can interface with many popular software packages. EVS can read and write AutoCAD Dxf files, ESRI shapefiles, and can directly access ODBC compliant databases (provided ODBC 32 is installed on the clients' computer). Environmental database software products such as EarthSoft's Equis for Windows and GIS Solution's GIS/Key also support output to EVS. EVS can perform three-dimensional postprocessing and animation for ground water and solute transport modeling packages such as GeoAnalysis's EVS-SIM and ESI's Ground Water Vistas.

\subsection{Analytes and Environments}

EVS can analyze all types of analytes and geophysical data in any environment (e.g., soil, groundwater, surface water, air, etc.).

\subsection{EVS Pricing}

There are two functionally different versions of EVS, the standard and PRO versions. Additionally, EVS-PRO comes in two different licensing versions. Our fixed licensing uses a hardware key to license the software. The key may be moved, and the machine with the key (and the software and drivers installed) is licensed and fully functional. The standard version of EVS is only available as a fixed license at a price of $\$ 4,995$. The fixed license version of EVS-PRO is $\$ 9,995$.

The floating license version of EVS-PRO has steep discounts with quantity and a more complex pricing structure. The floating license uses a hardware key on the machine that serves licenses, but any machine on a (TCP/IP) network can run the software until the available seats are used up. The table below gives prices for six nominal configurations. Please call for a quotation on any quantity. Additional keys to better distribute licenses are available for $\$ 500$ each. 


\begin{tabular}{||c|c|c|c|c|c||}
\hline $\begin{array}{c}\text { Tier } \\
\text { Class }\end{array}$ & $\begin{array}{c}\text { Nominal } \\
\text { Seats }\end{array}$ & $\begin{array}{c}\text { Price for Seat } \\
\# 1\end{array}$ & $\begin{array}{c}\text { Additional } \\
\text { seats }\end{array}$ & $\begin{array}{c}\text { Price for Nominal } \\
\text { Number of Seats }\end{array}$ & $\begin{array}{c}\text { Effective Seat Price for } \\
\text { Nominal Seats }\end{array}$ \\
\hline \hline A & 1 & $\$ 13,500$ & $\$ 6,250$ & $\$ 13,500$ for 1 seat & $\$ 13,500$ \\
\hline B & 3 & $\$ 16,000$ & $\$ 4,000$ & $\$ 24,000$ for 3 seats & $\$ 8,000$ \\
\hline C & 8 & $\$ 23,000$ & $\$ 3,000$ & $\$ 44,000$ for 8 seats & $\$ 4,153$ \\
\hline D & 17 & $\$ 41,800$ & $\$ 1,800$ & $\$ 70,600$ for 17 seats & $\$ 2,971$ \\
\hline E & 34 & $\$ 51,500$ & $\$ 1,500$ & $\$ 101,000$ for 34 seats & $\$ 2,000$ \\
\hline F & 100 & $\$ 101,000$ & $\$ 1,000$ & $\$ 200,000$ for 100 seats & \\
\hline
\end{tabular}

Annual software maintenance, updates and telephonic and e-mail tech support is included for the first year. Additional years are currently $12 \%$ of software list price. One year of technical support with software maintenance and upgrades is included in the purchase.

\subsection{EVS Training Requirements}

The majority of EVS users are self-trained using the printed and on-line workbooks and tutorials. C Tech offers formal advanced training classes. The three-day class covers the operation of the approximately150 modules in EVS and covers advanced animation techniques. The cost for the training class is $\$ 1,500$ per student. Customized training sessions at customer facilities are also available at consulting rates.

\subsubsection{History of EVS}

EVS development began in 1991. Much of the technology employed in our visualization techniques was the outgrowth of DOD and DOE weapons technology. C Tech Development Corporation was previously involved in solid mechanics simulations related to explosives research. The development of this technology required substantial time-based animation and three-dimensional visualization. In $1991 \mathrm{C}$ Tech became involved in a very large finite element mine dewatering simulation for a major gold mining company in the U.S. As a result of that involvement we recognized a need for better visualization tools to support the environmental engineering market. During that first year we began developing a software system to address the needs of environmental assessment, ground water, solute transport, air pollution modeling, and geologic modeling. That development has continued nonstop driven by user inputs and a creative group of geologists, environmental engineers, and software Developers.

Our current assessment for the industry need is even stronger than when we started in 1991. $\mathrm{C}$ Tech has invested more than 30 man-years in the development of EVS's tools specifically for this market. Additionally, there has been more than 100 man-years invested in the fundamental visualization technology which served as the original foundation of EVS. 


\subsubsection{EVS Applications}

EVS was developed to meet the needs of the geologist, environmental engineer, and environmental program manager as they relate to:

- $\quad$ Site assessment: determination of the optimal locations for collecting data in order to best determine the spatial extent of contamination at the lowest possible cost.

- $\quad$ Site evaluation: determination of the spatial extent of contamination, quantification of the mass and volume of contaminant plumes, and quantification of the statistical variation in the volume and mass estimates resulting from the current level of characterization.

- Geology: creation of a three-dimensional model of the site geology and determination of the relationship between the geology and the contaminant plumes. This understanding allows for better-targeted remediation plans, which consider the effect of geology on the migration and capture of contamination. Additionally EVS can compute plume volumes and masses on a (geologic) layer basis.

- Communication: visual communication of the site geology and contamination is critical. EVS provides high quality still and animated 3D visualization. EVS provides the ability to integrate geologic information, environmental contamination data, aerial photographs, site buildings, roads, etc.

\subsubsection{Advantages of EVS}

EVS is a modular software system geared to the needs of the environmental community. Its architecture provides the ability to customize applications for the most demanding application while preserving an ease of use that provides immediate productivity.

Research conducted by our customers has confirmed that EVS saves a lot of money on site assessment. Compared with sampling on a RCRA grid, EVS can save 30-80\%. EVS reduces the cost of assessment by focusing sampling on areas in the site where there is reason to suspect contamination, but where the confidence in the estimate is low. EVS also provides a quantitative method to determine when a site is adequately characterized. Our "Min-Max Plume" technology provides statistical bounding of plume volume or mass based upon a user input confidence.

Finally, EVS provides extensive visualization capabilities. Environmental problems are often information rich. However, this information must be communicated. Graphics provides data compression and translation. The compression is a natural by-product of visual communication and if the graphics are well designed, they provide translation of highly technical information into a form that can be understood by all parties involved in environmental decision making. 


\subsubsection{Operating Parameters of EVS}

EVS was developed to meet the data analysis needs of the geologist, environmental engineer, and environmental program manager. EVS can deal with virtually all types of data and environments. It is designed to be easy enough that nonspecialist personnel can use it (at a rudimentary level). However, the modular software architecture and breadth of tools provide EVS with comprehensive capabilities that can meet the needs of scientists and researchers.

One of EVS's greatest strengths is its integrated geostatistics that provide quantitative assessment of the quality of a site assessment (min-max plume technology) and identification of locations in a site which require additional investigation.

One of EVS's few limitations is its limited ability to model faulted geologic structures. To address this limitation, $C$ Tech has developed the Mining Visualization System (MVS). MVS is a superset of EVS-PRO and adds the ability to model more complex geologic structures and to deal with the additional data requirements common to mining operations.

\subsubsection{Groundwater $F X$}

Groundwater $F X$ is a decision support system intended to provide decision makers and analysts a means of evaluating environmental information relative to the nature and extent of groundwater contamination. It also supports monitor well network design and performance evaluations of remedial actions in groundwater. Key attributes of the tool include the ability to:

- $\quad$ quantify uncertainties in the nature and extent of groundwater contamination.

- $\quad$ quantify uncertainties relative to remedial actions (e.g., pump and treat performance).

- $\quad$ provide objective recommendations on the number and location of monitor wells to delineate a plume.

- $\quad$ provide visual feedback to a user on the nature of the contamination (e.g., concentration distribution, probability distribution of exceeding a drinking water standard).

- provide statistical information about the plume (e.g., average volume of contamination, standard deviation, etc.).

Groundwater $F X$ relies mainly on process model algorithms to assess the potential for contaminant migration and operations research methods to provide guidance on key decision analysis needs (e.g., recommended location of monitor wells). The Groundwater $F X$ methodology is an improvement over conventional groundwater modeling analysis approaches because of the following features: 1) allows the user to simulate the flow and transport of analytes from a source term, through the unsaturated zone, and within the saturated zone in three dimensions; 2) quantifies uncertainties through the use of stochastic simulation techniques; 3 ) honors hydraulic conductivity information and explicitly accounts for spatial variability through the use of geostatistical routines; 4) honors observed water quality data, thereby providing a type of built-in calibration method; and 5) provides objective guidance on monitor well placement (rather than using expert judgment). 
Currently, Groundwater $F X$ has versions that run on Windows95, WindowsNT, and Macintosh platforms. The software is written mainly in two languages: Fortran for the mathematical operations and $\mathrm{C}++$ for the graphical user interface (GUI) functions. Development software was chosen for ease of use in porting to different platforms. The recommended computer configuration for running the Groundwater $F X$ software on PC platforms is approximately $50 \mathrm{Mb}$ of hard-disk space for the program, about $100 \mathrm{Mb}+$ of storage space for model runs, about $64 \mathrm{Mb}$ of RAM, and a reasonable speed Pentium processor (> $100 \mathrm{Mhz}$ ).

The Groundwater $F X$ code is designed to provide decision analysis information on single analytes associated with contamination in groundwater. The methodology is based on a number of elements, including: 1) the use of fate and transport simulators for the source term, vadose zone, and the saturated zone (a 3-D finite difference model for flow and advective-dispersive solute transport); 2) geostatistics to simulate spatial variability; 3) Latin Hypercube Sampling (LHS) and Monte Carlo simulation techniques to efficiently quantify uncertainties; 4) a statistical conditioning algorithm to assure that observed water quality information are honored; 5) visual display capabilities that allow a user to assess the uncertainties; and 6) an operations research algorithm for monitor well network design. For multiple analytes of concern, multiple model runs must be performed. Though some investigators have used geostatistical approaches to analyze groundwater plume data, Decision $F X$ recommends the use of mass-conservative process modeling methods to address these issues. Thus, GroundwaterFX simulates the physics of flow and transport processes providing better understanding of the nature and extent of contamination, and quite often with fewer data points than a statistical or geostatistical approach would require.

Decision $F X$ is currently utilizing Groundwater $F X$ in consulting venues. The tool is undergoing enhancements and will likely be ready for commercial sales in early 1999. Decision $F X$ hopes to market the software for about $\$ 1000$ per copy. Training and user support are also desired, but the cost of such programs has not been established yet. At this time it is believed that a single license with Decision $F X$ will be all that is necessary to purchase and use the software, and that no sublicensing of other packages will be necessary.

\subsubsection{History of Groundwater $F X$}

Groundwater $F X$ is an exclusive product of Decision $F X$, Inc. Groundwater $F X$ is an outgrowth of the code called the Groundwater Analysis and Network Design Tool, or GANDT, developed at Sandia National Laboratories with funding from the Department of Energy (DOE). Decision $F X$ has the license to commercialize GANDT and use it for commercial purposes. The GANDT code was developed for use in the Environmental Restoration arena to save time and money compared to conventional approaches for groundwater analysis and plume delineation. Decision $F X$ is planning to utilize Groundwater $F X$ for conventional environmental compliance initiatives under RCRA and Superfund, but has also begun work on applications to Brownfields redevelopment issues. The tool has been used to demonstrate the potential for significant cost savings at DOE sites where conventional approaches would have cost millions of dollars in unnecessary expenditures. Groundwater $F X$ has also been used in the commercial sector to meet needs in the mining industry and for a case with solvent contamination associated with the electronics industry. Cost savings associated with characterization costs and cleanup optimizations have been demonstrated. A single Brownfields site evaluation has been performed with Groundwater $F X$. 


\subsubsection{Groundwater $F X$ Applications}

Groundwater $F X$ is intended to provide decision makers with defensible information on monitor well network design and groundwater contaminant plume definition. In an ideal situation the following process flow would be recommended to address the key needs for an investigation of contaminant nature and extent:

- $\quad$ Assemble and analyze any existing data pertaining to the site.

- Develop a conceptual model(s) of the site and the appropriate input parameter sets for the Groundwater $F X$ code.

- $\quad$ Utilize Groundwater $F X$ to analyze the fate and transport of contaminants from the source term and through the groundwater system. Condition simulations on available information (e.g., hydraulic conductivity data, water quality data). Provide the decision maker with maps of the average concentration distribution for the contaminants of concern, its standard deviation, variance, and coefficient of variation, and the probability distribution of exceeding a user specified concentration threshold (e.g., the drinking water standard, MCL). Also, use Groundwater $F X$ to provide statistics on the uncertainty associated with the volume of contamination.

- If risk-based decision making is part of the process, utilize information from Groundwater $F X$ to determine a risk-based cleanup level (such as in an Alternate Concentration Limit, or ACL, approach). Use of Groundwater $F X$ results to evaluate risk associated with groundwater concentrations make it possible to explicitly account for risk uncertainty. An iterative sampling, analysis, and risk assessment approach with the code allows decision makers to reduce uncertainties to a manageable level while optimizing risk-based decision criteria.

- Use Groundwater $F X$ information to determine if additional monitor well locations are warranted. If so, use the operations research methods to provide guidance on monitor well network enhancements (i.e., numbers and locations of additional wells desired). This optimization process utilizes information on probabilistic results and risk-based guidelines to reduce uncertainties in the knowledge of the nature and extent of contamination. The process may or may not include cost metrics (note that under RCRA cost is not allowed as a decision driver during characterization).

- $\quad$ Construct additional monitor wells and collect water quality data. The process of analyzing the data, updating the risk-based analysis (if appropriate), and determining when enough data have been collected for the decisions under consideration is best done in an iterative fashion.

- Utilize the information from this process flow to perform cost-benefit analyses of remedial alternatives, including land use decisions.

The Groundwater $F X$ methodology may be employed for uses other than those associated with delineating the nature and extent of contamination and optimizing a monitor well network. For instance, the user may be interested in evaluating alternative groundwater remediation strategies and their likelihood of success, which could be done explicitly by GroundwaterFX. Corrective actions such as natural attenuation (a very popular option for both inorganics and biodegradable organics), ACL potential, as well as pump and treat evaluations have been evaluated with the Groundwater $F X$ tool. Such additional applications are desirable because the visual and statistical information 
regarding the nature and extent of contamination provided by the code is very important to decision makers, especially when the decision making group(s) are not from a technical background (e.g., stakeholders). The tool can also be used for verification purposes; when a site has been modeled through conventional methods, the Groundwater $F X$ methodology could be employed as an independent check on the model evaluation.

A good illustration of the use of this methodology comes from work done for the DOE's Uranium Mill Tailings Remedial Action (UMTRA) project. One of the UMTRA sites was baselined for a pump and treat cleanup operation due to the elevated concentrations of uranium and molybdenum. DecisionFX utilized GroundwaterFX to evaluate the likelihood of success of a natural attenuation option. The analysis showed that the site would meet the groundwater standards through natural attenuation mechanisms within a 100-year time frame, which is allowable under the Nuclear Regulatory Commission and EPA rules. GroundwaterFX was also used to develop the acceptable range of groundwater quality results to demonstrate that the site was in compliance over the 100-year long-term surveillance and monitoring period. The alternate corrective action, pump and treat, would have cost the DOE about $\$ 4.5 \mathrm{M}$ over a 20 -year period to comply with drinking water standards. Another UMTRA example consists of the use of GroundwaterFX for an Alternate Concentration Limit (ACL) analysis. The code was used to assess the likelihood of success of an ACL strategy and to define performance monitoring specifications. In this case about $\$ 1 \mathrm{M}$ was saved compared with a conventional pump and treat analysis. At Sandia National Laboratories, the methodology was used to convince regulators to retract a request to install 7 additional deep monitor wells at a landfill site which would have cost about $\$ 750 \mathrm{~K}$. In still another example of its use, GroundwaterFX was applied to a solvent contamination problem where the responsible party was doing little to clean up a large solvent plume. The analysis provided information on the lack of performance of the existing system, as well as the likelihood of success of implementing a more aggressive cleanup strategy. A costbenefit analysis was also utilized to justify the recommended action.

\subsubsection{Advantages of Groundwater $F X$}

The Groundwater $F X$ tool provides decision makers with the ability to explicitly estimate uncertainties in the nature and extent of groundwater contamination, to evaluate corrective action alternatives, to design a monitor well network utilizing state-of-the-art operations research methods, and to provide statistical information on the volume of contamination for use in optimizing cleanup options. It improves upon conventional groundwater modeling methods, because it: 1) explicitly accounts for the uncertainty associated with contaminant fate and transport under complex hydrogeologic conditions; 2) honors existing characterization and water quality data; and 3) provides guidance on monitor well network design. The Groundwater $F X$ methodology is more objective than professional judgment approaches for monitor well network design. In comparison to graphical display and mapping software, Groundwater $F X$ honors hydraulic conductivity and water quality data explicitly, honors the physics of fate and transport, and directly quantifies uncertainties, allowing probability information to be utilized in the monitor well network design and in visual display options. Overall, the Groundwater $F X$ methodology should provide most users and decision makers with a more defensible means of evaluating the nature and extent of groundwater contamination and monitor well network design than would conventional approaches. The explicit treatment of uncertainty is often indispensable in the decision making process. 


\subsubsection{Operating Parameters of Groundwater $F X$}

Groundwater $F X$ relies on a fairly large suite of data inputs to assess the fate and transport of contaminants in a subsurface hydrologic system. Information regarding source term parameters (e.g., initial concentrations of the contaminant), flow parameters (e.g., hydraulic conductivity), and solute transport parameters (e.g., sorption coefficient, radioactive decay constant) are important inputs to the Groundwater $F X$ models. However, given that the tool has the capability to quantify uncertainty, the input parameters may be estimated from a variety of sources and still provide reasonable estimates of plume behavior. Data may come from site information (e.g., sample analysis, aquifer tests), literature sources, or professional judgment. The fact that the methodology honors observed water quality data in the conditioning process means that reasonable simulation results are likely, even if the site is not characterized extensively. The complexity of a flow and transport system will likely have a direct bearing on the degree to which the site needs to be characterized. The system is not intended for use on fractured porous media flow or on sites where multi-phase contaminant interactions are important. Users of the system should have some fundamental training in groundwater modeling and uncertainty analysis techniques prior to deploying the system.

\subsubsection{Spatial Analysis Decision Assistance (SADA)}

Spatial Analysis and Decision Assistance (SADA) is a Windows 95 environmental software package that incorporates tools from various fields including visualization, geospatial analyses, statistical analysis, human health risk assessment, cost/benefit analysis, sampling design, and decision analysis into a dynamic and interactive environment. Each of these modules can be used independently or in an integrated fashion to address site-specific concerns in the characterization and remedial action design. SADA was designed to simplify and streamline several of the processes in environmental characterization and to bring the information together in a way that can help the user make decisions about their particular site in a quick and cost-effective manner. SADA may be found useful by anyone who needs to look at data within a spatial context. This includes:

- $\quad$ Statisticians

- $\quad$ Human Health Risk Assessors

- $\quad$ GIS/Visualization Users

- $\quad$ Project Managers

- $\quad$ Stakeholders

SADA has been developed by the University of Tennessee and will be available commercially by the end of 1998. For the latest changes in cost, training, and licensing requirements visit the SADA home page at http://risk.lsd.ornl.gov/.

At a minimum, the user should have a Pentium computer with 32MB RAM, a clock speed of $120 \mathrm{MHz}$, a disk drive with $15 \mathrm{MB}$ of free space and an SVGA monitor. To access the toxicity database updates (optional), the computer should be setup with access to the world wide web.

\subsubsection{SADA Applications}

\subsection{Visualization}


The visualization techniques in SADA were designed to be simple to use, easy to understand, and to facilitate the data exploration, modeling, and decision analysis components.

SADA provides two- and three-dimensional visualization. Two-dimensional information is presented as simple xy plots. Three-dimensional information is presented in 2D slices (layers) in the third dimension. The user can easily set the depth of each of these layers. The layer approach while not a true three-dimensional visualization provides a way to quickly see results in daily application. In addition, environmental data are often categorized by depth during remedial investigations (surface, subsurface, 0-1ft, 0-2ft, etc.) and SADA was designed to fit into this type of framework.

SADA can accept any map layer from a Geographic Information System (GIS) if saved in a Data eXchange Format (DXF). Multiple layers can be imported into SADA and the user can control the layer order and coloring scheme.

In addition, the user can select a subregion of the site to direct the analysis. This region is defined by a user-defined polygon with only the interior region considered in the analysis.

\subsection{Data Exploration}

SADA provides methods for quick and easy data exploration. Available tools include statistical analysis, visual database queries, and basic data screening exercises. All these tools can be applied to the entire site or any subset of the site. Similarly, they may be applied to all or some of the contaminants. In addition, the user may select any region of the site and immediately view the human health risk results for that region.

\subsection{Human Health Risk}

SADA provides the user with a full human health risk assessment module and associated databases. The risk models follow the EPA's Risk Assessment Guidance for Superfund (RAGS) and can be customized to fit site-specific exposure conditions. Updated toxicological databases and default scenario parameters can be downloaded over the web directly from SADA. The following landuse scenarios and exposure pathways are available for both radioactive and non-radioactive contaminants for calculating risk as well as data screening levels.

Landuse Scenarios

$$
\begin{array}{ll}
\text { - } & \text { Residential } \\
\text { - } & \text { Industrial } \\
\text { - } & \text { Agricultural } \\
\text { - } & \text { Recreational } \\
\hline & \text { Excavation }
\end{array}
$$

Exposure Pathways

$$
\begin{array}{ll}
- & \text { Ingestion } \\
- & \text { Inhalation }
\end{array}
$$


- Dermal contact

- $\quad$ External (radioactive)

- Food consumption

- $\quad$ Combined Exposure

\subsection{Geospatial Analysis}

Several tools are provided in SADA for performing a geospatial analysis. These tools include methods for measuring spatial correlation among data, modeling spatial correlation, and producing concentration, risk, probability, variance, and cleanup maps. Among these tools are four geospatial interpolators: ordinary kriging, indicator kriging, inverse distance, and nearest neighbor. Using these tools the user has access to concentration contour maps, probability maps, risk maps, and remedial design maps.

\subsection{Decision Analysis}

SADA's decision support tools include the following applications:

\section{Cost/Benefit}

SADA produces cost benefit curves that demonstrate the relationship between the cleanup goal (concentration or risk based) and the cost of remediation.

\section{$\underline{\text { Area of Concern }}$}

Based on the decision rule, SADA estimates the location of areas of concern. The decision rule includes components such as the cleanup goal, the level of confidence, and whether the goal applies to the entire site or any part of the site. These areas of concern can then serve as a basis for remedial action design.

\section{$\underline{\text { Sampling Designs }}$}

SADA allows the user to choose from a variety of strategies for determining where to collect data in the next round of sampling. Depending on the geospatial interpolator chosen, the following strategies are available.

\section{Adaptive Fill}

This approach is designed to spatially fill the gaps among existing data with new data points. This approach identifies the locations, which are yet unsampled and are the farthest from any other data point. These become the suggested locations for new samples. This method is the easiest to use and is independent of the geospatial interpolator chosen.

\section{Estimate Rank}


This approach selects new sample locations that are modeled to have high concentration levels relative to the existing data. The approach is available for any of the interpolation schemes. This approach can be useful for verifying the extent of hotspot regions.

\section{Variance Rank}

Variance rank selects new sample locations that have high estimation variances. This approach will suggest data collection in regions that may not be well characterized from a modeling perspective. This approach is available only with ordinary kriging.

\section{Percentile Rank}

This approach is in a sense a merger of the two previous approaches. It gives weight to both magnitude and variability and reduces the tendency to place data in well characterized hot spots as well as sparse areas with very low (or zero) measured concentration values.

\section{Uncertainty Rank}

This approach is the only one that is connected to the decision rule. This scheme places new sample locations in areas where there is the greatest uncertainty about exceeding the cleanup goal (block scale). This approach is useful for delineating the boundaries of an area of concern.

\subsubsection{Advantages of the SADA Technology}

The advantages of SADA are that it is easy to use and incorporates a large number of the models required in basic characterization and risk assessment into a single, stand-alone package. The program streamlines many of the steps required in the modeling process and automatically links them for the user. Most of the tools in SADA are laid out in a control panel format so that the user can see what is available at all times, and how changes in the model input affect the modeling or decision results. The online help system is comprehensive and contains help movies that show onscreen how to achieve a series of steps.

SADA comes with a toxicity profile database and a module that automatically attempts to match site contaminants to the database for the user. This reduces the task of determining CAS numbers, adjusting for varying changes in the contaminants spelling, and so forth. In addition, the customization of the scenario parameters is intuitive and visual.

The use of external GIS maps through the DXF format makes SADA independent of the GIS system in use and allows the user to continue modeling with the benefits of underlying maps.

In applications to date, SADA has been found to significantly reduce the amount of startup time and modeling efforts associated with site characterization and risk assessment. In addition, the results have been found to be self explanatory and easy to communicate to stakeholders.

\subsubsection{SADA Operating Parameters}


SADA is structured to handle any type of contaminant (radiological or hazardous) in subsurface systems. Currently, SADA does not consider transient conditions and performs the analysis based on the available data. There are no time-dependent fate and transport models for groundwater or surface water included in the SADA code package.

\subsubsection{Sampling $F X$}

Sampling $F X$ is a decision support system intended to provide decision makers and analysts a means of evaluating environmental information relative to the nature and extent of contamination in surface and subsurface soils. Key attributes of the tool include the ability to:

- $\quad$ quantify uncertainties in the nature and extent of soil contamination.

- $\quad$ provide objective recommendations on the number and location of sampling points to delineate the contamination.

- $\quad$ provide visual feedback to a user on the nature and extent of the contamination (e.g., concentration distribution, probability distribution of exceeding a soil guideline).

- $\quad$ provide statistical information about the plume (e.g., average volume of contamination, standard deviation, etc.).

Sampling $F X$ relies mainly on geostatistical algorithms (from the GSLIB code set) to analyze spatial aspects of soil contamination data and operations research methods to provide guidance on key decision analysis needs (e.g., recommended location of samples). Sampling $F X$ is an improvement over conventional sampling and analysis approaches because it provides information on spatial variability (something that traditional statistical approaches ignore) and provides objective guidance on sampling placement (rather than using expert judgment).

Currently, Sampling $F X$ has versions that run on Windows95, WindowsNT, and Macintosh platforms. The software is written mainly in two languages: Fortran for the mathematical operations and $\mathrm{C}++$ for the graphical user interface (GUI) functions. Development software was chosen for ease of use in transferring between different platforms. The recommended computer configuration for running the Sampling $F X$ software on the PC platforms is approximately $15 \mathrm{Mb}$ of hard-disk space for the program, about $10 \mathrm{Mb}+$ of storage space for model runs, about $32 \mathrm{Mb}$ of RAM, and a reasonable speed Pentium processor (> $100 \mathrm{Mhz}$ ).

The Sampling $F X$ code is intended for use in providing decision analysis information on single analytes associated with contamination in surface or subsurface soils. The methodology is based on geostatistics, and therefore is applicable to other parameters exhibiting spatial correlation (e.g., hydraulic conductivity distributions). For multiple analytes of concern, multiple model runs must be performed.

Decision $F X$ is currently utilizing Sampling $F X$ in consulting venues. The tool is undergoing enhancements and will likely be ready for commercial sales in early 1999 . Decision $F X$ hopes to market the software for about $\$ 500$ per copy. Training and user support are also desired, but the cost of such programs has not been established yet. At this time it is believed that a single license with Decision $F X$ will be all that is necessary to purchase and use the software, and that no sublicensing of other packages will be necessary. 


\subsubsection{History of Sampling $F X$}

Sampling $F X$ is an exclusive product of Decision $F X$, Inc. Sampling $F X$ is an outgrowth of the code called the Optimization Program To Minimize Analytical Sampling, or OPTMAS, developed at Sandia National Laboratories with funding from the Department of Energy (DOE). Decision $F X$ has the license to commercialize the OPTMAS technology. The OPTMAS code was developed for use in the Environmental Restoration arena to save time and money compared to conventional approaches to sampling for determining contamination extent. Decision $F X$ is planning to utilize Sampling $F X$ for conventional environmental compliance initiatives under RCRA and Superfund. The tool has been used to demonstrate the potential for significant cost savings at DOE sites where large acres of contamination are present. Recently, Decision $F X$ has begun using Sampling $F X$ on a Brownfields investigation that should lead to the eventual cleanup and reuse of a contaminated property in Milwaukee, WI. 


\subsubsection{Sampling $F X$ Applications}

Sampling $F X$ is intended to provide decision makers with defensible information on sampling network design and extent of soil contamination. In an ideal situation the following process flow would be recommended to address key needs for an investigation of soil contamination extent:

- $\quad$ Assemble and analyze any existing data pertaining to the site.

- $\quad$ Collect and analyze an initial set of soil samples (e.g., 20 samples) at the site based on historical information, professional judgment, statistical sampling methods (e.g., grid sampling), or random sampling (an option that exists in Sampling $F X$ to get the user started).

- $\quad$ Utilize Sampling $F X$ to analyze the soil sample data and identify any potential correlations in the spatial distribution of the data. Provide the decision maker with maps of the average concentration distribution for the contaminants of concern, its standard deviation, variance, and coefficient of variation, and the probability distribution of exceeding a user specified concentration threshold (e.g., a soil screening guideline). Also, use Sampling $F X$ to provide statistics on the uncertainty associated with the volume of contamination.

- If risk analysis is part of the process, utilize Sampling $F X$ estimates to determine a riskbased cleanup level. Sampling $F X$ accounts for uncertainty in risk by virtue of the fact that it directly addresses soil contamination variability and uncertainty. If future land use is unclear, risk-based concentration thresholds can take into account land use decisions and be used to balance costs. The difference in soil cleanup guidelines can be substantial for different land use exposures and therefore may have a marked impact on the extent of sampling and the degree of cleanup. An iterative sampling, analysis, and risk assessment approach with the code serves to reduce uncertainties to a manageable level while optimizing risk-based cleanup criteria.

- Use Sampling $F X$ information to determine if additional sampling locations are warranted. If so, use operations research methods in the code to provide guidance on sampling network enhancements (i.e., numbers and locations of additional samples to collect). This optimization process utilizes information on probabilistic results and risk-based guidelines to reduce uncertainties in the knowledge of the extent of contamination. The process may or may not include cost metrics (note that, under RCRA, cost is not allowed as a decision driver during characterization).

- Collect additional samples and analyze. Utilize the concentration data to update the risk-based cleanup guidelines to determine when enough data have been collected to make decisions regarding future cleanup.

- Utilize the information from the process flow to perform cost-benefit analyses of remedial alternatives, including land use decisions.

Other site investigation approaches may be enhanced with the Sampling $F X$ methodology. For instance, the user and/or regulator may be most comfortable with a traditional sampling approach (e.g., grid sampling), but would benefit from the spatial analysis of the data provided by SamplingFX. In this case, the decision maker would still be provided with the various mapping options mentioned above (e.g., the average concentration distribution for the contaminants of concern, the probability distribution of exceeding a user specified concentration threshold). Visual and statistical information 
regarding the nature and extent of contamination is very important to decision makers, especially when the decision making group(s) is not from a technical background (e.g., stakeholders).

A good illustration of the use of this methodology comes from an analysis performed on a lead contaminated firing site at Sandia National Laboratories. A conventional grid sampling approach was taken to sample soils at the site. Approximately 350 samples were collected to define the nature and extent of lead contamination. An independent analysis of the data with Sampling $F X$ with only 60 samples was able to provide the same uncertainty information in the nature and extent of contamination as was achieved with the grid approach. The relative costs of the two sampling strategies were quite different, with the grid sampling scheme being six times more expensive. The Sampling $F X$ methodology also provided decision makers with maps for delineating cleanup zones under different land use criteria. Cost estimates for cleanup alternatives can incorporate the uncertainty information provided by Sampling $F X$. In the case of the lead firing site, regulators accepted a less stringent industrial cleanup scenario in lieu of a residential land use scenario, wherein cost differences between the two cleanup options were $\$ 90 \mathrm{~K} \pm \$ 10 \mathrm{~K}$ versus $\$ 2.5 \mathrm{M} \pm \$ 500 \mathrm{~K}$, respectively.

\subsubsection{Advantages of Sampling $F X$}

The Sampling $F X$ tool provides decision makers with the ability to explicitly estimate uncertainties in the nature and extent of soil contamination, to design a sampling network utilizing state-of-the-art operations research methods, and to provide statistical information on the volume of contamination for use in optimizing cleanup options. Compared to conventional statistical sampling design methods, this approach explicitly accounts for the spatial aspects of the contamination distribution. This typically results in fewer samples collected, at least on larger sites of interest. The Sampling $F X$ methodology is more objective than conventional sampling schemes based on expert judgment. Sampling $F X$ honors the observed concentration data explicitly and is based on geostatistical techniques for quantifying uncertainties, allowing probability information to be utilized in the sampling network design and in visual displays. Estimates of contaminant magnitudes and volumes from this geostatistical simulator are more useful and defensible, as the explicit treatment of uncertainty is often indispensable in the decision making process.

\subsubsection{Operating Parameters of Sampling $F X$}

Sampling $F X$ relies mainly on soil concentration data as input to the system. Coordinates of sampling locations and the analytical results from the laboratory or field screening methods are the primary data requirements. A variography package is used to evaluate statistical trends in the spatial data. A geostatistical model is used to perform simulations on the observed data to predict a range of outcomes for spatial variability in the desired parameter (e.g., lead concentrations). The geostatistical model honors the observed data in making predictions of the spatial variability of the analyte of interest. Risk-based soil concentration guidelines are important input for visual display purposes and for optimizing sampling network design. The system is not intended for use on sites where less than 20 data points are expected, or where the contamination is confined to a very small area (e.g., along a narrow pipeline). Users of the system should have some fundamental training in statistics and geostatistics prior to employing the system. 


\subsubsection{SitePro}

SitePro is a software application that helps environmental professionals more quickly and comprehensively characterize and manage environmental sites. SitePro integrates database, GIS, CAD, mapping, contouring, boring logs, cross-sections, graphing, imaging, and reporting in one application. This integration provides support for decisions pertaining to monitoring and remediation. Environmental professionals use SitePro to manage various environmental issues and media including contaminated soil and water, air emissions, wastewater, and health and safety parameters. SitePro allows environmental professionals to manage and share their site data using a single file.

SitePro's open, flexible, and scalable architecture includes data exchange tools that make it easy to import and export more than 25 industry standard map and data formats. In addition, SitePro's fully customizable lookup tables allow users to easily modify the database. For instance, users can easily customize SitePro with their own chemicals, soil types, monitoring parameters, object types, etc. SitePro integrates with Microsoft Office ${ }^{\mathrm{TM}}$, and Microsoft Exchange $^{\mathrm{TM}}$.

Additional tools and services help SitePro users quickly achieve the productivity benefits of SitePro. For example, SitePro includes a demonstration site file ("ChemPlant") with a corresponding 3-hour tutorial that shows users how to import data, analyze it, and create reports and maps. SitePro's extensive on-line Help and User's Guide make it fast and easy for users to find the information they need. Environmental Software's web support (www.envsoft.com) provides quick tips, in-depth application notes for power users, and up to date information about current releases. Environmental Software's customer service department assists users via e-mail, fax, and phone. Environmental Software offers a suite of training options, including their most popular 1-day SitePro Certification training class. Environmental Software also offers consulting services at competitive rates for data management, site data loading, customization, and software integration.

SitePro supports the Microsoft Windows 95, 98, and NT operating systems. System requirements include a 90-MHz Pentium Processor with a minimum of $32 \mathrm{MB}$ of RAM (48 MB RAM for NT Workstations), $50 \mathrm{MB}$ of available hard disk space, and a 1.44 MB floppy disk drive (CD-ROM preferred). SitePro will be available as a client/server application in the fourth quarter of 1998.

SitePro is part of a modular and integrated Environmental Management Information System (EMIS) product line developed by Environmental Software. SitePro sells for $\$ 2,295^{\mathrm{a}}$ (U.S.) and is available directly from Environmental Software. The company also offers an upgrade, maintenance, and service package for $\$ 275$ per year which is required for new users.

\subsubsection{History of SitePro}

Environmental Software began developing the fundamental technology behind SitePro in 1996. The application was built utilizing Microsoft's 32-bit Windows Open System Architecture. SitePro seamlessly integrates the fundamental tools that environmental professionals need: GIS, CAD,

a Price listed is for the desktop version. Volume discounts are available and server products are priced separately. 
database, mapping, analysis, and reporting. Since the initial release of SitePro 1.0, the product has continuously evolved through version and maintenance upgrades. Environmental Software works very closely with customers to improve existing features and develop new ones.

\subsubsection{SitePro Applications}

SitePro manages all phases of site management - from initial assessment through monitoring and restoration. SitePro is successfully being used for a variety of projects including site mapping, rapid site assessments and characterizations, monitoring and operations management, cost-effective data analysis, and reporting.

SitePro is currently in use at many sites including federal Superfund cleanups, state and federal government site restorations, and in Global 2000 companies worldwide. SitePro users include manufacturers, consultants, government agencies, educators, and public interest groups.

\section{$\underline{\text { Site Mapping }}$}

SitePro is used to quickly and professionally map site and facility features. SitePro's easy-touse GIS and CAD tools allow users to add or enhance an existing site map or generate a new map from scratch. Site features can quickly be mapped with SitePro's map drawing and generation tools and/or entering GPS or survey data.

\section{$\underline{\text { Rapid Site Assessment and Characterization }}$}

SitePro is successfully being used in the field and office to support rapid site assessment and characterization projects. SitePro supports field data entry and analysis to make faster and betterinformed field decisions. Users may quickly generate contour maps during soil and groundwater investigations and soil-gas surveys. Hydrographs and chemical concentration curves are easily generated with SitePro's graphing tool. Report-ready boring logs, well construction logs, and crosssections can easily be generated during site characterization activities to save time and money and improve site understanding. Also, SitePro's database and report queries allow users to quickly display and compare field data with historic data and maps.

\section{Operations Management}

SitePro includes operations data management tools to manage equipment information and runtime data. Users can log operation on/off periods and document operation status information. Operation reports can be quickly generated to view historical operations information and help develop trends for improved future operations.

\section{Cost-Effective Data Presentation and Reporting}

SitePro is an effective tool for conducting site presentations. Map layers, objects, and labels can easily be turned on and off to focus presentation information. Map contours can be generated on the fly and displayed on the map. Double clicking on a map object (e.g., a monitoring well) hotlinks the user to all the site data for the selected object. 
SitePro includes numerous features that automate data output material such as tabular reports, graphs, maps, boring and well construction logs, and cross-sections. SitePro's report-quality output may be printed or saved as an external file format.

\subsubsection{Advantages of SitePro}

A key advantage with SitePro's technology is that it integrates functions commonly performed by environmental professionals that would otherwise require several databases and applications to perform. Another key advantage is that SitePro provides templates and other tools to automate repetitive or tedious tasks resulting in productivity gains of $30 \%$ and higher. In many cases, SitePro has allowed users to perform data analyses that would previously have been cost-prohibitive.

As summarized in the following table, SitePro utilizes state of the art technology that offer numerous benefits to SitePro users.

\begin{tabular}{|l|l|}
\hline \multicolumn{1}{|c|}{ Technology } & \multicolumn{1}{|c|}{ Advantages } \\
\hline Open architecture & $\begin{array}{l}\text { Allows easy import and export of data and } \\
\text { map formats. SitePro supports more than } 25 \\
\text { industry standard formats. }\end{array}$ \\
\hline $\begin{array}{l}\text { Scalable database (scales from Microsoft Jet } \\
\text { to SQL Server) }\end{array}$ & $\begin{array}{l}\text { SitePro's database technology is designed to } \\
\text { scale from individual desktop computers to } \\
\text { multiple-server and web networks. }\end{array}$ \\
\hline 32-Bit COM-compliant technology & $\begin{array}{l}\text { Provides a robust platform that maximizes } \\
\text { performance with Microsoft's operating } \\
\text { systems (95, 98, and NT). }\end{array}$ \\
\hline $\begin{array}{l}\text { Distributed Internet Applications architecture } \\
\text { (Windows DNA) }\end{array}$ & $\begin{array}{l}\text { By using the DNA framework, SitePro } \\
\text { includes modern, scalable, multi-tier EMIS } \\
\text { applications that can be delivered over any } \\
\text { network. }\end{array}$ \\
\hline Universal Data Accessing technologies & $\begin{array}{l}\text { By using UDA technologies (ODBC, } \\
\text { OLE/dB, ADO/RDS, et. al.) SitePro } \\
\text { customers can access all types of information } \\
\text { (including relational and non-relational data) } \\
\text { from their desktop or across their enterprise. }\end{array}$ \\
\hline Desktop and Client/Server Environments & $\begin{array}{l}\text { SitePro is scalable from the desktop to the } \\
\text { enterprise. SitePro utilizes both WIN32 } \\
\text { clients and Internet clients which can access } \\
\text { information hosted on Microsoft BackOffice } \\
\text { platforms as well as workgroups and local } \\
\text { clients. }\end{array}$ \\
\hline
\end{tabular}


Environmental Software has earned the prestigious status of Microsoft Certified Solution Provider (MCSP). As an MCSP, Environmental Software receives unequaled access to Microsoft's state of the art technologies which, for our customers, means price/performance leadership and a steady growth path to the future. 


\subsubsection{SitePro Operating Parameters}

SitePro is designed for environmental professionals with varying backgrounds and experience. SitePro does not require GIS, database, or CAD knowledge or experience. It is not designed to replace specialized GIS or CAD experts or systems but rather to allow environmental professionals to work with those experts and systems more effectively and more meaningfully. SitePro's security features allow administrative users to specify access privileges for users.

\subsubsection{Summary}

The preceding sections are the Developer descriptions of their software and its capabilities. The list includes six different software programs, (ESRI's ArcView, Environmental Visualization System, Groundwater $F X$, SADA, Sampling $F X$, and SitePro). Each section discusses the capabilities of the software, their development and application's history, advantages of the software, and range of applicability. Two software packages, ESRI's ArcView and SitePro, will address the visualization and cost/benefit endpoints. These software packages integrate data from a number of sources and present the data in visual form to assist in understanding the problem. The other software packages will be used to address visualization, sample optimization, and cost/benefit analysis problems. These DSS often incorporate geostatistical data analysis software, optimization theory software, or flow and transport software in the system to assist in the data analysis process.

\subsection{Demonstration Performance Goals}

One important objective of Decision Support Software is to integrate data and models to produce information that supports an environmental decision. Therefore, the overriding performance goal in this demonstration is to provide a credible analysis. Credibility of a computer analysis is built on four components (Van der Heijde, 1996), as follows:

- $\quad$ good data.

- $\quad$ adequate and reliable software.

- $\quad$ adequate conceptualization of the site.

- $\quad$ well-executed problem analysis.

In this demonstration, it will be assumed that the data are of good quality. This removes several issues which are beyond control of the DSS from the analysis. Problems associated with site conceptualization will be minimized by the description of the site and data supplied to the Developers. Thus, this demonstration will primarily test the adequacy of the software and the skills of the analyst. In this demonstration, the DSS will be operated by the Developers. Therefore, the limiting factor in the analysis should be the adequacy of the software.

Even if the software is found to be adequate in this demonstration, a credible analysis of any environmental problem will require all four components being present. If any of the other factors are missing, erroneous results may be obtained from the software.

The fact that we are attempting to define and measure credibility makes this demonstration far different from most demonstrations in this program in which measurements devices are evaluated. 
In the typical programs, quality can be measured in a quantitative and statistical manner. This is not quite true for DSS. While there will be some quantitative measures there will also be many qualitative measures.

Section 3.2.1 describes the metrics for evaluation of the DSS's ability to support a credible analysis. In addition, a number of secondary objectives will be used to evaluate the software. This will include documentation of software, training and technical support, ease of use of the software, efficiency and representativeness, and flexibility to interface with other computer codes. These are discussed in sections 3.2.2 through 3.2.5.

\subsubsection{Decision Support}

The Developers will be asked to use their software to answer environmental questions. For visualization tools, integration of geologic data, contaminant data, and site maps to define the contamination region at specified concentrations will be requested. For software tools that address other endpoints, an example of the type of question that will be asked is: define the area in which the contamination is above 100, 50 and $10 \mathrm{ppb}$ at the $90 \%$ confidence limit ( $90 \%$ confidence that the concentration exceeds the threshold value).

The criterion for evaluation is how credible is the analysis that supports the decision. The evaluation will be based on several points including:

- documentation of the use of the models, input parameters, and assumptions.

- $\quad$ presentation of the results in a clear and consistent manner.

- $\quad$ comparison of model results with the data and baseline analyses.

- $\quad$ evaluation of the use of the models.

- $\quad$ use of multiple lines of reasoning to support the decision.

The following sections in 3.2.1 provide more detail on each of these topics.

\subsubsection{Documentation of the Analysis}

The Developers must supply a concise description of the models used in the analysis, key input parameters, and modeling assumptions. Documentation requirements are provided in Section 9.

\subsubsection{Presentation of Results}

The results of the analysis should be provided in a manner that supports the decision. Presentation of the results should include a narrative description of the problem, objectives of the analysis, procedures used in the analysis, conclusions of the analysis with technical justification of the conclusions, and graphical display of the analysis. Information should be supplied in electronic and printed form. Documentation requirements for the results are presented in Section 9.

3.2.1.3 Comparison of Projected Results with the Data 
Developers will be given a limited data set on the site. Data points not provided to the Developers will provide a method of checking the consistency of the analysis. While quantitative comparisons between predictions and the data or baseline analyses may be evaluated (root mean square deviation, negative difference, positive difference, mean error, etc.), due to the inherent variability in the system, they will not be the only measure of goodness of fit. Qualitative evaluations of how well the model projections reproduce the trends in the data will also be performed.

Estimates of the mass and volume of contamination will be compared to the baseline analyses to evaluate the ability of the software to determine the extent of contamination.

\subsubsection{Evaluation of the Use of the Models}

Based on observations obtained during the demonstration and the documentation supplied by the Developers, the use of the models will be evaluated and compared to standard practices. Issues in proper use of the models include spatial and temporal discretization, solution techniques, and parameter selection.

For sample optimization studies the evaluation will include an examination of the amount of data required for the analysis.

This analysis will be performed as a quality assurance check to determine if standard practices are followed. This will help further define any discrepancies between model projections and the data arise due to operator actions or the model itself.

\subsubsection{Multiple Lines of Reasoning}

Environmental decisions are often made with uncertainties due to an incomplete understanding of the problem and lack of information, time, and/or resources. Therefore, decisions based on multiple lines of reasoning will be noted in contrast to those based on a single analysis. Multiple lines of reasoning may incorporate statistical analyses which, in addition to providing an answer, provide an estimate of the probability that the answer is correct. Multiple lines of reasoning may also incorporate alternative conceptual models or in the absence of a statistical analysis, multiple simulations with different parameter sets. The software will be evaluated on its capabilities to support multiple lines of reasoning. 


\subsubsection{Documentation of Software}

The software will be evaluated in terms of its documentation. The documentation should include detailed instructions on how to use the code, examples of verification tests performed with the code, a discussion of all output files generated by the code and how the output files may be used by other programs (for example, it can be directly imported into the Surfer graphics program), and a review of the theory behind the technical approach used in the code.

\subsubsection{Training and Technical Support}

The Developers will be asked to list the necessary background knowledge base necessary to successfully operate the code (i.e., basic understanding of hydrology, geology, geostatics, etc. along with proficiency in auxiliary software used by the code and in use of operating systems (e.g. Unix, Windows NT, etc.). A discussion of training and technical support provided by the Developers will also be required. Much of this information has been presented in Section 3.1.

\subsubsection{Ease of Use}

Ease of use is one of the most important factors to users of computer software. Ease of use will be evaluated based on examination of the codes operation, the presence of adequate on-line help, the availability for obtaining technical support, the flexibility to change input parameters and data bases used by the code, and time required for an experienced user to setup the model and prepare the analysis (that is, input preparation time, time required to run the simulation, and time required to prepare graphical output).

In a further attempt to understand the operation of the software packages, the Developers will be requested to provide a brief (maximum of four hours) training course to a few individuals. These individuals will then be asked to attempt to use the code to perform a few simple tasks. These tasks will be performed without further guidance from the Developers, however, documentation and on-line help will be permitted. This evaluation will be focused on how easy it is to use the code, not on how well the code evaluates environmental problems.

It is recognized that there is a wide range in the level of sophistication and modeling in these codes, and in many cases four hours will be insufficient training to use the full range of options of the software. The purpose of the training is not to become a proficient user of the software but rather to understand the required training level and ease of use of the software. The Developers will focus on a few key points which they feel can be adequately taught within the limited time frame.

\subsubsection{Efficiency and Representativeness}

Efficiency will be evaluated through the resource requirements used to evaluate the problems. This will be assessed through the number of problems completed as a function of time required for the analysis and machine capabilities. 
Representativeness is a measure of the software's ability to represent a wide range of environmental conditions and will be evaluated through the range of conditions over which the software is tested and the number of problems analyzed.

\subsubsection{Flexibility to Interface with other Software}

Data may be stored in many formats. The software should be able to read standard ASCII text files and common graphic and database file formats. The ability to import and export data in multiple formats will be evaluated.

In addition, for software that is only demonstrating the Visualization aspects of this program, the ability to interface with other software packages that perform the other endpoints of the demonstration will be examined. For example, if the program prepares a subsurface visualization of geologic and hydrologic structures and the zone of contamination, translating this information into a form that can be used directly by a flow and transport code or a sample optimization code will be noted. The evaluation will examine the capability to perform the task with existing software on a demand basis without further software modifications. The ability to develop software interfaces to translate the data into the proper form will be noted, however, since this would require additional development work, it will not be evaluated. 


\subsection{DEMONSTRATION SITE DESCRIPTIONS}

This section discusses the history and characteristics of the demonstration sites. In this demonstration data have been collected from several demonstration sites. The intent is to provide a suite of problems for each endpoint (visualization, sample optimization, and cost/benefit) to test various aspects of the software's capabilities. Developers will not be required to analyze all of the sites. A minimum of three test problems is required for the demonstration. For the most part, the data is from actual sites and the data has been obtained through measurement in the field. To protect the confidentiality of the data, the sites will not be referred to by name. Instead, they will be given a letter and number designation (i.e., Site A-1, Site B-1, etc.). The letter defines the site, and the number refers to the specific problem on the site. The following sections contain a general description of the site history, type of environmental problem being addressed, and site characteristics. Detailed data sets will be supplied with the test problems at the demonstration.

\subsection{Site Descriptions and Hydrogeologic Characteristics}

The following descriptions provide baseline data on the operating history, contaminants, and hydrogeologic characteristics of the sites. All sites can be represented as a porous media, however, there are differing levels of complexity at the sites which will test different aspects of the DSS's capabilities. The wide range of contaminants and sites will help to test the DSS's performance over a range of environmental conditions.

\subsubsection{Site A}

Site A has been in operation since the late 1950's. It is an industrial machine plant which uses solvents and degreasing agents. It overlies an important aquifer which supplies more than 2.7 million gallons of water per day for industrial, commercial, and residential use. A large region of the aquifer has been contaminated due to releases of VOCs from the machine plant. Source control is considered an important remediation objective to prevent further contamination.

Site A is located in the northeastern U.S. In 1983 it was discovered that soil and groundwater was contaminated with VOCs (tetracholorethylene, tricholoethylene and vinyl chloride) and some heavy metals (chromium, nickel, and lead). Site characterization and monitoring activities were initiated and it was determined that agricultural and industrial activities from nearby industries were identified as sources of contamination. The primary concern is VOC contamination in the aquifer and the potential migration to public water supplies.

The aquifer in the area consists primarily of stratified sand and gravel with some basal till and is overlain in places by alluvium. Hydraulic conductivities in the aquifer range from 5 to 500 feet per day, but throughout most of its extent range from 50 to 250 feet per day. The zones of highest hydraulic conductivity coincide with sediments deposited by glacial meltwaters originating from drainage channels to the north and northwest near a river. The maximum saturated thickness of the aquifer exceeds 100 feet near its eastern extent but generally ranges from 0 to 60 feet. Laterally, the aquifer is bounded by till-covered bedrock uplands. The river located to the north and northwest is gently sloping and the aquifer is drained by the river and its tributaries. 


\subsubsection{Site B}

Site B is located in a sparsely populated area of the southern United States on a 547-ha $(1,350$ acre) site about $4.8 \mathrm{~km}$ (3 mi) south of a large river. Site B is typical of many metal fabrication or industrial facilities because it has numerous potential sources of contamination (e.g., material storage areas, process activity areas, service facilities, and waste management areas). As with any manufacturing facility, laboratory activities and cleaning operations can introduce solvents and other organic chemicals into the environment. Industrial operations include feed and withdrawal of material from the primary process, treatment of water for both potable and cooling purposes, steam generation for heating purposes, decontamination of equipment removed from the plant for maintenance or replacement, recovery of heavy metals from various waste materials, and treatment of industrial wastes. As a result of these activities, soil, groundwater, and surface waters are contaminated. Of primary concern is off-site migration of groundwater contaminated with organic compounds and radionuclides.

Site B is about $4.8 \mathrm{~km}(3 \mathrm{mi})$ south of a large river and approximately $16 \mathrm{~km}(10 \mathrm{mi})$ west of a city of more than 25,000 people. Approximately $90 \%$ of the area within an $8 \mathrm{~km}(5 \mathrm{mi})$ radius of the site is agricultural or forested land.

Site B covers about 540 hectares (ha). The main plant area covers 300 ha. The remaining 240 ha are maintained as a buffer zone surrounding the site. Active waste-management areas within the buffer zone include a raw-water treatment plant, a residential landfill, an inert landfill, and two industrial treatment lagoons. In addition, various inactive units, including a former sanitary landfill and several concrete rubble piles, are located outside the main plant area. Approximately 850 ha $(2,100$ acres $)$ of land beyond the buffer zone area are leased by the state.

Site B is situated in an area characterized by a relatively flat terrain. Elevations vary from about 300 to $450 \mathrm{ft}$ above mean sea level $(\mathrm{msl})$ on the site property, with the ground surface sloping at a rate of approximately $5.1 \mathrm{~m} / \mathrm{km}(27 \mathrm{ft} / \mathrm{mi})$ toward the river north of the site. Two main topographic features dominate the landscape in the surrounding area: (1) the loess-covered plains,

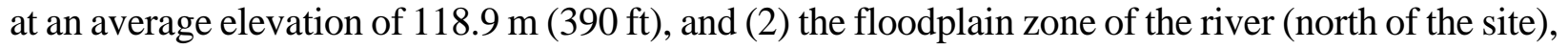

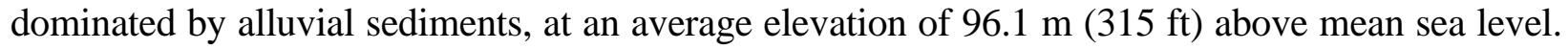
The terrain of the site is slightly modified by the dendritic drainage systems associated with the two principal streams in the area. These northerly flowing streams have eroded small valleys that are approximately $6.1 \mathrm{~m}(20 \mathrm{ft})$ below the adjacent plain.

The geologic framework in the region consists of Mississippian carbonate bedrock overlain by unconsolidated Cretaceous, Tertiary, and Quartenary sediments. The oldest unconsolidated sediments beneath the site are the weathered Mississippian rubble zone and the Upper Cretaceous Tuscaloosa Formation, which together are approximately $6.1 \mathrm{~m}(20 \mathrm{ft})$ thick. Unconformably overlying these formations are the Upper Cretaceous McNairy Formation and Paleocene Clayton Formation, which consist of interbedded and interlensing sands, silts, and clays. Totaling $68.6 \mathrm{~m}$ (225 $\mathrm{ft}$ ) thick, these two formations have been grouped together and termed the McNairy Formation. In the southern portion of the site, the Paleocene Porters Creek Clay and the Eocene deposits of sand and silt overlie the McNairy. 
The continental deposits can be subdivided into two components: a lower gravel or sandy gravel unit that varies in thickness form 0 to $105 \mathrm{ft}$ and an upper clay-sand unit with a comparable range of thickness. The top of the gravel facies unit occurs at a depth of approximately 40 to $65 \mathrm{ft}$ in the vicinity of Site B. The clay facies of the continental deposits are believed to consist of discontinuous, fine sand lenses enclosed by the dominant clay.

The surficial deposit at the site is a 1.5-7.6-m (5-25 ft) thick clayey silt of aeolian origin known as loess. The youngest sediments consist of recent alluvial floodplain material or fill. The soils that formed in the loess and alluvial floodplain are mainly silt loams and clay loams. Loess, which consists of clayey, sandy silt, and silty clay, outcrops at the surface over a majority of the area encompassed by Site B. Thickness of the unit varies from $0 \mathrm{~m}$ in the small creek valleys to $10.6 \mathrm{~m}$ (35 ft) immediately northeast of the site.

The Upper Late Deposits occur at a depth of up to $10.6 \mathrm{~m}$ (35 ft) below ground surface (bgs) and outcrop along the banks of a small stream northeast of the site. The thickness ranges from 6.1 $\mathrm{m}(20 \mathrm{ft})$ south of the Creek Terrace to $18.3 \mathrm{~m}(60 \mathrm{ft})$ north of it. Sand, silt, and clay with some gravel compose the Upper Late Deposits immediately northwest of the Creek Terrace.

\subsubsection{Site D}

Site D is located in the western United States. It consists of about 3,000 acres of land bounded by municipal areas on the west and southwest and unincorporated areas on northwest and east. Site D has been an active industrial facility since its initial operations in 1936. Operations have included maintenance and repair of aircraft and recently the maintenance and repair of communications equipment and electronics.

Site D has engaged in a wide variety of operations involving the use, storage, and disposal of hazardous materials. These operations included aircraft storage, aircraft maintenance using racks, hangars, machine shops and washracks, aircraft painting, wastewater treatment, fuel/oil storage, electronics testing and repair, generator dismantling, aircraft painting, firing range, ammunition storage and fire training. Materials used include industrial solvents, caustic cleaners, electroplating chemicals, heavy metals, polychlorinated biphenyls (PCB), low-level radioactive wastes, and a variety of fuel oils and lubricants. Accidental spills and releases of these materials have resulted in contaminated soil, groundwater, and surface water. Of primary concern are VOC contaminated soil and groundwater as well as soils contaminated with metals.

Surface features at Site D include open grassland, creeks, drainage, and vernal pools, as well as industrial and residential areas. The land surface is a relatively flat plain that slopes gently to the west. Surface elevations range from about 75 feet above mean sea level (msl) on the eastern side to about 50 feet msl on the western side.

Soil in the vadose zone, or the unsaturated zone between the surface and the groundwater table, is composed of interbedded layers of sands, silts, and clays. This zone is currently approximately 90 to 105 feet thick. Clays and hardpan layers slow, but do not halt, infiltration of liquids. 
Groundwater is encountered at about 90 to 105 feet bgs, and flows generally south-southwest. However, the water table was at one time much higher; water levels have declined continuously for about 50 years because of overdrafting by irrigation, supply, and extraction wells. In areas of groundwater contamination, changes in flow direction and the declining water table have produced a contaminant "smear zone." As groundwater levels declined, some of the groundwater contaminants remained in the newly exposed portion of the vadose zone. These contaminants have remained as gases in soil pore spaces or as liquid films.

The groundwater beneath Site D behaves as one hydrogeologic unit. That is, only one interconnected aquifer, or water-bearing zone, is present. To help analyze groundwater and contaminant movement, this one aquifer has been divided into five groundwater monitoring zones. The zones are called A, B, C, D, and E, from shallowest to deepest. Although the zones are connected, water within each zone moves more readily horizontally than it moves vertically between zones. By measuring changes in groundwater flow and contaminant migration within each zone, a better understanding of the system is obtained allowing improved monitoring and remediation strategies to be developed.

\subsubsection{Site N}

Site $\mathrm{N}$ is located in a sparsely populated area of the southern United States. Site $\mathrm{N}$ is typical of many metal fabrication or industrial facilities because it has numerous potential sources of contamination (e.g., material storage areas, process activity areas, service facilities, and waste management areas). As with any manufacturing facility, laboratory activities and cleaning operations can introduce solvents and other organic chemicals into the environment. Industrial operations include feed and withdrawal of material from the primary process, recovery of heavy metals from various waste materials, and treatment of industrial wastes. Of primary concern is contamination of the surface soils by heavy metals.

\subsubsection{Site $S$}

Site $\mathrm{S}$ has been in operation since 1966. It is an industrial fertilizer plant producing pesticides, fertilizer, and using industrial solvents such as carbon tetrachloride and trichlorethene (TCE). Recently, a small leak was discovered in a seal leading to an exterior storage tank which contained chlordane. The tank has been in use since 1978. However, it is not known when the seal failed. Measurements of the chlordane concentration in groundwater have been as high as several ppm a few hundred feet downgradient from the well. The site boundary is approximately 5000 feet from the storage tank. In addition, there are several regions on the site with soil contamination by heavy metals.

The leaking seal is located about thirty feet above the water table and five feet below grade. The unsaturated zone is composed of a coarse sandy soil with minimal presence of silt or clay. Unsaturated zone hydraulic characteristics have not been measured for the site.

The regional groundwater system is characterized by a layered sequence of Pleistocene and Cretaceous gravel, sand, silt, and clay deposits. The aquifer system has been designated by EPA as 
a sole source aquifer system. The stratigraphic sequence contains three major aquifers and two confining units, in ascending order:

- $\quad$ Lawrence aquifer.

- Jones clay confining unit.

- Monahan aquifer.

- $\quad$ Smiths clay confining unit.

Near the site, the groundwater divide is north of the site and flow is generally toward the south. Contamination originating from the site is in the Glacial aquifer which is between 150 and 200 feet thick. This is an unconfined water table aquifer and is an important source of water for public and private wells in the area. The outwash deposits of sand and gravel are highly permeable and hydraulic conductivities generally range from $100-300 \mathrm{ft} /$ day. The general flow direction is to the south at about $1 \mathrm{ft} /$ day in the horizontal direction and $10 \mathrm{ft} / \mathrm{yr}(0.036 \mathrm{ft} / \mathrm{d})$ in the vertical direction. Vertical flow changes in the vicinity of the Jones and Smiths confining layer.

\subsubsection{Site T}

Site T was developed in the 1950's as an area to store agricultural equipment as well as fertilizers, pesticides, herbicides, and insecticides. Mixing operations (fertilizers and pesticides or herbicides and insecticides) were discontinued or replaced in the 1980's when levels of pesticides and herbicides in soil and wastewater were determined to be of concern. Site T consists of 18 acres located in an undeveloped area of the western United States with the nearest residence being approximately 0.5 miles north of the site.

The site is situated in a valley which has a very minor relief. Surface elevations vary on the order of 5 feet over a distance of several thousand feet. Creeks and drainage are cut into the land surface by several feet with relatively steep banks. Regional topography shows surface drainage flows from west to east, but most overland flow is focused to creek beds and ditches.

Site $\mathrm{T}$ is underlain by alluvial deposits of silt, clay, sand and gravel. The sand and gravel occur as thin, discontinuous lenses in the vadose zone and upper saturated zone. The hydrogeology is a 3-dimensional flow system with two discontinuous silty-sand water bearing zones. Zone T-1 is the shallower of the two and lies at a depth of approximately 35 feet bgs. The T- 2 zone lies at a depth of approximately 60 feet bgs and is separated from the T- 1 zone by a clay aquitard. A laterally continuous regional aquifer underlies the T-2 zone at approximately 105 feet bgs.

The source of soil and groundwater contamination is primarily an earthen, unlined disposal basin which was used during the pesticide handling and mixing operations for disposal of rinsates, residual chemicals, and various storage containers. 1,2-dibromoethane (Ethylene dibromide, EDB), 1,2-dicholoropropane (DCP) and 1,2-dibromo-3-chloropropance (DBCP) are the contaminants of concern in soil and groundwater.

\subsection{Problem Descriptions}


A general description of the problems that will be used for each site follows. The description includes the site designator, media (soil or groundwater), dimensionality of the problem (2 or 3 dimensions), types of contaminants, and the endpoints that may be evaluated with the data set. In many test problems multiple contaminants will be present. The objective of the following discussion is to provide a general description of the range and types of problems that will be evaluated. More detailed discussions of the types of problems are provided in Section 6 and in table 6.1

Site A-1 Sample optimization problem for a 3-dimensional groundwater contamination problem with VOCs.

Site A-2 Cost/benefit problem for a 3-dimensional groundwater contamination problem with VOCs.

Site B-1 Sample optimization combined with a cost/benefit problem for a 2-dimensional ground water problem with radionuclides and industrial solvents (VOCs). The aquifer is thick and contains clay lenses which influence flow.

Site D-1 Sample optimization combined with a cost/benefit problem for a 3-dimensional groundwater VOC contamination problem. Groundwater flow at this site occurs in one thick hydrogeologic unit.

Site N-1 Sample optimization problem for a 2-dimensional soil contamination problem with heavy metals.

Site N-2 Cost/benefit problem for a 2-dimensional soil contamination problem with heavy metals.

Site S-1 Sample optimization problem for a 3-dimensional groundwater VOC (Carbon Tetrachloride) contamination problem.

Site S-2 Cost/benefit problem for a 3-dimensional groundwater pesticide (chlordane) contamination problem.

Site T-1 Sample optimization problem for a 3-dimensional groundwater soil contamination problem with pesticides (EDB) and VOCs (carbon tetrachloride). Visualization analysis will be required for the problem.

Site T-2 Cost/benefit problem for a 3-dimensional groundwater contamination problem with pesticides (EDB) and VOCs (carbon tetrachloride). Visualization analysis will be required for the problem.

Visualization analysis will be required as part of all problems.

In the preceding descriptions it is stated, in many cases, that both sample optimization and cost/benefit problems will be developed. These problems will involve different data sets which do not overlap. For example, the cost/benefit problem can be defined for one set of contaminants and the sample optimization for another. In addition, after thorough examination of the data, the five or six best sample optimization and cost/benefit problems will be selected for the demonstration. 


\subsection{CONFIRMATORY PROCESS}

The verification process is founded on comparison of the DSS predictions based on a limited data set to three measures:

- the data.

- $\quad$ baseline analysis on the complete data set.

- $\quad$ baseline analysis on the identical data set supplied to the Developers.

The DSS outputs (documentation and figures) will be evaluated against the performance goals of this demonstration (Section 3.2). In all cases, the Developers will be provided with a subset of the data and asked to produce an analysis of the environmental problem. Data not supplied to the Developers will be used to check the analysis. In this demonstration, most baseline data sets will originate from field data, and it is assumed that the data are accurate and adequately represent the environmental conditions. Even so, there is a degree of uncertainty associated with using field data. This uncertainty arises from the variability inherent in natural systems and lack of control or poor understanding of the sources of contamination. For this reason, in a few cases, synthetic problems with known solutions will be used as the baseline for comparison. These tests will permit a higher degree of confidence in the evaluation of technical accuracy. In addition, existing data sets may be modified on an as needed basis to permit testing of the software's capabilities.

For each test problem, the data will be reviewed and analyzed by staff from Oak Ridge National Laboratory (ORNL) to determine its usefulness as a baseline. In the event the data cannot be easily and accurately modeled (for example, highly localized zones of contamination along fractures in the host rock), the data set will be removed from consideration for this demonstration. The Developers, verification organizations (BNL and ORNL), and EPA will work closely to develop the baselines to be used for comparison.

\subsection{Problem Selection}

The primary objective of the DSS demonstration program is to test the capability of the selected DSS to address the three endpoints defined in section 1.0, which are visualization, sample optimization and cost/benefit analysis. To accomplish this test cases have been developed. These test cases were, to the extent possible, taken from existing environmental contamination problems. The test cases offer differing levels of complexity and test different aspects of the capabilities of the software. Sections 4.3 and 6.2 discuss the test problems in more detail.

Most of the data used for testing will originate from actual sites. As a benchmark for testing decision support tools, the data set must be complete enough to accurately define the location and extent of the contamination zone. This limits the choices to sites which are extensively characterized. The data should accurately delineate the three-dimensional boundary of the contaminated zone. Detailed characterization of the contamination is the most important criterion for selection of a data set. In some cases, data measurements over a period of time will be used in the test problems. Other site characterization data will be necessary to solve the problem, including:

- $\quad$ soil structure data (bore hole data). 
- $\quad$ hydrology data for each soil layer (flow rates, conductivity, porosity).

- transport data for each soil layer (sorption, dispersion, biodegradation rates, radioactive decay rates).

Although preference will be given to using field data as supplied, it may be necessary to make alterations to the data to test different aspects of the DSS. These alterations will be primarily to sample locations and/or contaminant concentration data. Any alterations to the actual data will be documented and the justification for the alteration will be provided.

This data will be supplied at a level of detail consistent with the field data. This implies that many data will be given with a range of values (e.g., conductivity is $10-50 \mathrm{ft} /$ day).

Test problems will be selected on a range of analytes and environmental conditions to test the DSS's range of capabilities. All aqueous contaminants considered for the test problems will exist as a dissolved component in the groundwater (i.e., single phase flow and transport). All sites selected for the demonstration are free from fractures or have limited fractures which will allow modeling the subsurface flow and contaminant transport using an equivalent porous medium. The following types of problems will be prepared.

- a two-dimensional surface soil contamination problem.

- $\quad$ a three-dimensional surface/subsurface soil contamination problem.

- a groundwater contamination problem - flow adequately represented in twodimensions.

- $\quad$ a groundwater contamination problem - multiple flow paths, layered geologic media with a fully three-dimensional flow field.

- $\quad$ a soil and groundwater contamination problem - simple flow field, one- or twodimensional.

These problems are described in more detail in Section 4 which provides descriptions of the sites and their operating history and Section 6 where the experimental test plan is described.

\subsection{Baseline Analysis}

One measure of the performance of the DSS technologies will be a comparison of model predictions with the full data set. To assist in the comparison, a baseline analysis will be performed for the entire data set by ORNL. In addition, ORNL will perform an analysis on the data set supplied to the Developers. These two analyses will form the basis of comparison for evaluating the technical performance of the Decision Support Software. The comparison will contain both qualitative and quantitative measures as discussed in Section 3.2 and 5.4.

For sample optimization studies in which the Developers will be permitted to request additional data, an analysis will be performed with the final data set provided to each Developer after the demonstration is complete. This will permit an examination of the effectiveness of the optimization through an evaluation of whether collecting more data would have changed the decision.

\subsection{Contingency Analysis}


Analysis of actual environmental problems will have uncertainties. To build confidence in the analyses used as a baseline for comparison, selected test problems will be supplied on an as needed basis to others to provide independent results for comparison.

\subsection{Analysis of Results}

The major objective of this demonstration is to evaluate the capabilities of the software to support environmental decisions. This is a complex, subjective task. To analyze the results, the verification organization will base the evaluation on the following criteria:

- documentation of the use of the models, input parameters, and assumptions.

- $\quad$ presentation of the results in a clear and consistent manner.

- $\quad$ comparison of model results with the data and baseline analysis.

- $\quad$ evaluation of the use of the models.

- $\quad$ use of multiple lines of reasoning to support the decision.

These criteria have been discussed in detail in Section 3.2. Guidance on the methods of evaluation for the qualitative criteria is provided in Section 6.2.1. Guidance on the level of documentation and presentation of results is provided in Section 9. Comparison of model results with the data will contain a qualitative evaluation between the baseline analysis and the Developer's prediction. In addition, a quantitative comparison between the data and the model projections will be performed. The quantitative comparison will be examined for trends in the data, such as consistently under-predicting the field data. The methods used for quantitative analysis are in the following sections.

\subsubsection{Methods of DSS Output Analysis}

The quantitative evaluation of the analysis will be a comparison of the output with the actual data. In addition, comparisons will be made with the baseline analysis using the entire data set and another analysis using the same data set as supplied to the Developers. The following sections describe the evaluation procedure for DSS output comparisons to be made for the Visualization, Sample Optimization, and Cost/Benefit problems. 


\subsubsection{Evaluation of Interpolated Data}

Regardless of the endpoint, it will be necessary for all models to take the existing data set and interpolate or extrapolate data to translate a series of discrete points into a continuous representation of the system. For example, subsurface structures (i.e., geologic strata, and contaminant data) will be supplied as a discrete number of data points. The DSS will have to interpolate between this sparse set of data points to estimate the location of these features. In this case, quantitative comparisons will be performed between:

- the data supplied to the Developer and the Developer's projections. Absolute agreement between the two may not necessarily be achieved, depending upon the methods selected to obtain a continuous representation of the data. However, clear documentation of the sequence of steps to translate the discrete data into a continuous representation is required.

- $\quad$ the data not supplied to the Developer and the Developer's projections.

- $\quad$ baseline analysis performed with the entire data set and the Developer's projections

- baseline analysis performed with the data set provided to the Developer and the Developer's projections.

The last two comparisons will provide information on whether differences between the data and the DSS results are caused by variations in the actual data or due to the approaches used to model the data.

Emphasis in the comparisons will focus on the regions of the problem domain which are most sensitive to the decision. For example, consider a problem in which the decision is specified as identifying the region in which the concentration is above $5 \mathrm{ppb}$ with $90 \%$ confidence. In regions in which the concentration is two or three orders of magnitude below the threshold, it is not important to accurately predict concentrations and little weight will be placed on how well the model predictions match the data. In regions where the concentration is near or above the threshold, it is more important to accurately estimate concentrations and this region is where the most stringent quantitative evaluations of accuracy will occur. Additional comparisons will be performed with the baseline analysis performed on the data set supplied to the Developers and the complete data set.

In addition, the Developers will be asked to supply an estimate of the volume (area) and contaminant mass contained in contamination regions above some specified threshold concentration. Both the predicted volume and mass provide an integrated average for the problem and provide another method for obtaining a quantitative comparison between the baseline and Developer's analysis.

Quantitative comparisons will involve calculation of root mean square deviation, and positive and negative differences between the data and the model predictions (bias). While these quantitative comparisons will provide a measure of the technical accuracy in the solution, it is still not an absolute measure of the accuracy of the models. Natural variability in the system will produce variability in the data which cannot be reproduced by the DSS in all cases. However, the ability of the DSS to reproduce the data exactly is not necessary for making a decision on sample optimization or 
cost/benefit analysis. The DSS must be able to reproduce the trends in the data to provide a technically defensible rationale for making the decision.

To overcome the concern that the natural system cannot be modeled exactly, test problems will be supplied to the Developers for which an exact solution is known (e.g., synthetic data sets). These test problems will assist in evaluating the technical accuracy of the solution.

The DSS Developers' predictions will also be examined for regions in which there is a large discrepancy between the data and the DSS predictions. These regions will indicate domains in which the DSS may have problems in reproducing the data. This may be a result of having insufficient characterization data (i.e., the data may indicate a hot spot or outlier in one region which is inconsistent with the other data) or a result of the DSS having difficulty in the analysis. The comparison between the baseline analysis and the Developer's analysis will be essential in this case to resolve the cause of the discrepancy.

\subsubsection{Visualization Endpoint}

In some cases, the data will be known with a high degree of accuracy, for example, the location of surface structures. In this case, the evaluation will determine if the surface structures are in the correct location. This involves comparison of the known locations with the locations as represented in the model. In cases when the data do not support an exact representation of the system, for example, contaminant concentration data or subsurface stratigraphy data, predictions based on the analysis will be compared with the data directly.

\subsubsection{Sample Optimization Endpoint}

In a sample optimization problem, Developers will be given a limited amount of data and asked to define the minimum region in which the contamination is above a threshold value with a specified level of confidence. Initially, the data will be insufficient to draw conclusions and more data will be required. The Developers will then request more data from the verification organization. They will then repeat the process with the additional data until they can support the decision with a specified level of confidence. It is expected that concentration contour maps at specified probability levels will be provided as output as part of the analysis. These maps will be used as a basis for comparison as discussed in the previous section on interpolated data.

The DSS technologies will be evaluated to determine if the solution for the sample optimization problem was answered with the specified level of accuracy and the minimum amount of data (i.e., the most cost effective sampling scheme). A comparison will be made between the DSS results and the results of the baseline analysis performed on the entire data set. In addition, a comparison will be made between the DSS results and a baseline analysis performed using only the data supplied to the Developer. These two baselines will provide the foundation for evaluating whether enough samples were taken to support the decision.

\subsubsection{Cost/Benefit Endpoint}


The Developers will be provided with three options for performing cost/benefit calculations. The options will all include calculation of the location and volume (mass) of contamination as a function of i) confidence level for specified concentration levels, ii) clean-up level for specified confidence levels, or iii) human health risk as a function of concentration level. The Developers will select which options they will address. The Developers may address more than one option on a single problem. These benefits will be compared against the baseline analyses performed with the complete data set and the Developer's data set. 


\subsection{DEMONSTRATION DESIGN}

This section discusses the objectives of the demonstration, factors that must be considered to meet the performance objectives, and the information that BNL and ORNL will use to evaluate the results of the demonstration.

\subsection{Objectives}

The primary objectives of this demonstration are to evaluate Decision Support Software in the following areas: (1) the effectiveness in integrating data and models to produce information that supports the decision, and (2) the information and approach used to support the analysis. Secondary objectives for this demonstration are to evaluate DSS for its reliability, resource requirements, representativeness, and ease of operation. The evaluation process will compare the performance of the technology against the performance goals as stated in Section 3.2.

\subsection{Experimental Design}

The objective of this demonstration is to conduct an independent evaluation of Decision Support Software's capability to evaluate three common endpoints of environmental remediation problems: Visualization, Sample Optimization, and Cost/Benefit Analysis. For the purposes of this demonstration, these endpoints will be evaluated as follows:

Visualization: Visualization software will be evaluated in terms of the ability to integrate site and contamination data in a coherent and accurate fashion which aids in understanding the contamination problem. Tools used in visualization can range from data display in graphical or contour form to integrating site maps and aerial photos into the results.

Sample Optimization: Sample optimization will be evaluated for soil and groundwater contamination problems in terms of predicting the minimum number and location of samples needed to define a contaminated region with a specified level of confidence.

Cost/Benefit Analysis: Cost/Benefit analysis software will be evaluated on soil and groundwater contamination problems. In general, cost/benefit analysis is defined as the cost optimization relative to a benefit.

It is important to emphasize that the software tested in the development does not need to address all three endpoints to participate. Software will be evaluated only on the portions of the problem to which it is applied.

The demonstration will rely on the Developers' analyses of multiple test problems with different levels of complexity. The majority of the test problems are based on measured environmental conditions at actual sites. The use of actual data makes quantitative evaluation of the software challenging because of variability in natural systems. To address this issue, a few test problems with known solutions will be prepared. These problems will provide a basis for quantitative evaluation of the accuracy of the DSS systems. As a minimum, all developers will be asked to 
analyze three problems for each endpoint. It is anticipated that time will permit evaluation of more than three problems.

For each test problem the Developer chooses to analyze, the Developer will be supplied a data set containing information on geologic structure, hydrologic flow parameters, contaminant data (in some problems at multiple points in time) and surface structure. In addition, a brief narrative description of the site history in terms of the contaminants under study will be provided. Each Developer will be given the same identical data set to begin the problem. Which data to use will depend on the software's capabilities and not all data will be relevant for each participant. For example, if the software cannot take borehole data to develop the geologic structure, the Developer can choose to not use the data.

For sample optimization test problems the Developers will be supplied with a limited set of contamination data. The software should define the region where the contamination is above a specified concentration. Initially, due to the sparseness of the data, this will be an extremely large volume (area). The Developers will then be asked to suggest sample locations to reduce the estimate of the volume (area) of the contaminated area. The process will proceed iteratively until the Developer feels collection of additional data will not substantially change the estimate of contaminated volume.

In cost/benefit analysis problems the Developers will be given the data and asked to answer one of the three following questions.

- Where and how large is the region in which the contamination concentration exceeds a threshold value? Based on the analysis, the Developer will recommend collecting more data or clean-up of a region. The Developers will be asked to assess the uncertainty in their predictions. This cost/benefit analysis is defined as a Type 1 analysis in Table 6.1. This analysis can be accomplished by interpolation, statistical, or geostatistical approaches.

- Where and how large is the region in which the contamination concentration exceeds a set of threshold values with one or more confidence levels? Based on the analysis, the Developer will recommend collecting more data or clean-up of a region. Guidance will be given on the criteria for selecting a cleanup level and a confidence level which will be used to support the cleanup decision. This is defined as a Type 2 cost/benefit analysis in Table 6.1. This problem is generally analyzed using geostatistical techniques.

- What is the estimate of human health risk as a function of contamination levels for a specified confidence? On-site and off-site exposure pathways will be specified as part of the problem definition. Based on the analysis, the Developer will be asked to estimate the human health risk for specified exposure pathways. This is defined as a Type 3 cost/benefit analysis in Table 6.1.

The choice of which question(s) to answer is left to the Developers. However, the Developers must identify which of these questions will be evaluated by their respective software. 
Table 6.1 summarizes the potential test problems by site, media, contaminant, and computational endpoint. The table indicates that sample optimization and cost/benefit problems will be developed for each site. This indicates that there is sufficient data to develop a test problem.

Table 6.2 provides a list of the types of data that will be supplied for the pre-demonstration and demonstration test problems. The information in table 6.2 referring to the dimensionality of the problem refers to the data. It is possible to analyze systems listed as 3-D with a 2-D model. In these cases, it will be the analysts obligation to explain the rationale for the modeling approach used. 
Table 6.1 Site and Problem Descriptions

\begin{tabular}{|c|c|c|c|c|c|}
\hline $\begin{array}{c}\text { Site } \\
\text { Designator }\end{array}$ & $\begin{array}{c}\text { Problem } \\
\text { Description }\end{array}$ & Contaminant(s) & Visualization & $\begin{array}{c}\text { Sample } \\
\text { Optimization }\end{array}$ & Cost/Benefit \\
\hline A-1 & $\begin{array}{l}\text { 3-D } \\
\text { groundwater }\end{array}$ & VOCs & $\mathrm{X}$ & $\mathrm{X}$ & \\
\hline A-2 & $\begin{array}{l}\text { 3-D } \\
\text { groundwater }\end{array}$ & VOCs & $\mathrm{X}$ & & Type $1,2,3$ \\
\hline B-1 & $\begin{array}{l}\text { 2-D } \\
\text { groundwater }\end{array}$ & VOCs, Rads & $\mathrm{X}$ & $\mathrm{X}$ & Type $1,2,3$ \\
\hline D-1 & $\begin{array}{l}\text { 3-D soil and } \\
\text { groundwater }\end{array}$ & VOCs & $X$ & $X$ & Type 1,2 \\
\hline N-1 & 2-D soils & Metals & $\mathrm{X}$ & $X$ & \\
\hline $\mathrm{N}-2$ & 2-D soils & Metals & $\mathrm{X}$ & & Type $1,2,3$ \\
\hline$S-1$ & $\begin{array}{l}\text { 3-D } \\
\text { groundwater }\end{array}$ & Carbon Tetrachloride & & $\mathrm{X}$ & \\
\hline$S-2$ & $\begin{array}{l}3-\mathrm{D} \\
\text { groundwater }\end{array}$ & Chlordane & & & Type $1,2,3$ \\
\hline $\mathrm{T}-1$ & 3-D soils & VOCs, pesticides & $\mathrm{X}$ & $\mathrm{X}$ & \\
\hline $\mathrm{T}-2$ & $\begin{array}{l}\text { 3-D } \\
\text { groundwater }\end{array}$ & VOCs, pesticides & $X$ & & Type 1,2 \\
\hline
\end{tabular}


Table 6.2 List of Data to be Supplied as Part of the Test Problems

Site History

Surface Structure

Sample Locations

Contaminants

Geology

Hydrogeology

Transport Parameters

Human Health Risk industrial operations, environmental settings, site descriptions (Sections 4.1 and 4.2)

road and building locations, topography, aerial photos

$\mathrm{x}, \mathrm{y}, \mathrm{z}$ coordinates for:

soil surface samples

soil borings

groundwater wells

concentration data as a function of $\mathrm{x}, \mathrm{y}$, and $\mathrm{z}$ for metals, inorganics, organics, radioactive contaminants

soil boring profiles, bedrock stratigraphy

all problems: hydraulic conductivities in each stratigraphic unit, head measurements, and locations

simplified hydrogeology problems: flow rates as a function of $\mathrm{x}, \mathrm{y}$, and $\mathrm{z}$

$\mathrm{Kd}$, degradation rates, dispersion coefficients, porosity, bulk density

exposure pathways and parameters, exposed populations 


\subsubsection{Qualitative Factors}

The evaluation of the DSS will rely heavily on examination of qualitative factors. This arises naturally from the major objective of this program which is to evaluate how well the software can be used to support the decision. This is a qualitative objective. Section 3.2 discussed the evaluation criteria in detail. Qualitative evaluation criteria include:

- $\quad$ documentation of the theory and models implemented in the software.

- documentation of the parameters and assumptions used in the analysis.

- documentation of the results of the analysis and the rationale to support the decision.

- $\quad$ use of multiple lines of reasoning (alternate parameter sets, conceptual models, etc.) to support the decision.

- $\quad$ evaluation of ease of use.

Information will be collected on each of the above items and used for evaluation. Section 9 provides a more detailed discussion of information requirements for this demonstration.

Evaluation of model documentation will be performed through comparison with standard software quality assurance guidelines (e.g., ANSI Standards for documentation of computer codes) and standard documentation practices. Items to be looked at in the evaluation include a narrative of the program's capabilities, input requirements, external data base requirements, description of all output files generated by the code, use of default values, operating system requirements, verification problems, any software QA procedures applied to the code, and code maintenance and control.

Evaluation of the documentation of assumptions and data used in the code will be performed. The evaluation will focus on two aspects: reproducibility and following standard modeling practices. Reproducibility is defined for this demonstration as the ability to reproduce the results of the analysis from the information supplied. This will require clear description of all assumptions and data used in the analysis. Standard modeling practices will be evaluated in terms of the justification for parameter selection and modeling assumptions, (for example, grid size, interpolation parameters, etc.).

Evaluation of the results will emphasize the evidence used to support the final conclusions of the analysis. The rationale must be presented in a clear manner which is easily followed and supported by the results of the analysis. Use of multiple lines of reasoning to support the conclusion will be examined.

Ease of use will be evaluated during the demonstration using two approaches. The first is that a small group of people will undergo minimal training on the software and then attempt to use the software without further training. Second, during the demonstration members of the verification organization will interact with the Developers to gain insight on ease of use. This interaction will take the form of observation and discussion with the operators. It is requested that to the extent possible, the Developers explain each step of the analysis process as it is being performed.

Effect of operator experience on results 
This is an important issue for use of any software product. In this demonstration, the impact of having a poor operator will be minimized by having the software Developers operate their own software. This will enhance the ability to evaluate software's capability. Further, the test data and description of the site will be provided. This should help minimize data selection errors and conceptual model development errors. At the demonstration, members of the verification organization will be available to address questions and clarify areas of uncertainty about the problem.

\section{Effect of natural variability on results.}

Natural systems inherently exhibit variability. Using actual data leads to the problem that in supplying a partial data set to the Developers, it may be possible that the results will be skewed by the choice of data. This potential will be minimized by performing baseline analysis on the complete data set and on the partial data set supplied to the Developers. The baseline analyses will be compared and the data set provided to the Developers will be selected with an understanding of the effects of data selection on model predictions.

\subsubsection{Quantitative Factors}

Evaluations of quantitative factors related to accuracy of the solution have been discussed in detail in Section 5.4.1 and in Section 8.6. In addition, quantitative factors such as computational hardware and resource requirements used in the demonstration, will be examined. Resource requirements include manpower for the analysis, time to complete and document the analysis, computing time, and internet access.

It is recognized that in most applications of Decision Support Software, analysis time is a small fraction of the total time invested into the problem. Data collection, quality assurance on the data and other factors generally consume the major part of the effort and costs in environmental problems. However, the evaluation of these resource requirement factors will be conducted during this demonstration.

\subsection{Data Preparation}

ORNL is responsible for the collection of multiple data sets to be used as pre-demonstration and demonstration test problems. Data collection will occur by contacting the parties responsible for maintaining data at the various sites. Data will be supplied primarily in electronic format. Narrative descriptions of site history and other information will be supplied with the data.

In addition to data collection, the verification organization will perform baseline analysis of each data set. From each analysis, they will select a partial data set to supply to the Developers as test problems. The verification organization will re-analyze the problem based on the partial data sets to be supplied to the Developers. Analysis of the data performed by the verification organization will be used as a baseline for evaluation.

Data sets will be prepared in standard formats (e.g., ASCII text files, JPG graphics files, etc.) to be used in the demonstration. These data sets will be reviewed by ORNL and BNL for consistency with the original data sets and the objectives of the demonstration. 


\subsubsection{Pre-demonstration Test Problem}

ORNL will provide the pre-demonstration test problem to the Developers. The test problem will address either all three endpoints, or multiple test problems will be provided. The objectives of the pre-demonstration are:

- $\quad$ To provide the Developers with a sample problem with the level of complexity envisioned for the demonstration.

- To allow the Developers to process data from a typical problem in advance of the demonstration, and, if necessary, refine their technologies to provide alternative formats for accepting data or to suggest other formats for receiving data.

- To allow an evaluation of any unanticipated problems that may occur due to data transfer or problem definition.

The Developers are requested to provide a brief (one or two-page) report on the predemonstration. This report should discuss:

- $\quad$ the objectives of the problem (i.e., 2-D soil contamination sample optimization study).

- $\quad$ any problems with the data and problem specification.

- $\quad$ provide a few figures that demonstrate that the data was successfully incorporated into the DSS system.

- $\quad$ provide an estimate of the time required for the pre-demonstration analysis and the time required for a complete analysis of a similar problem with documentation as specified in Section 9.

Results of the pre-demonstration study performed by the Developers must be made available to the ORNL by August 24 or two weeks after the receipt of the test problem. This will allow time for analysis of the data and notification if problems exist. The results from the pre-demonstration study will be used to refine the final set of test problems.

\subsection{Demonstration Analysis}

The technology will be operated by the Developer, who will provide the results to the EPA, BNL, or ORNL. The Developer will be responsible for reducing the raw data into a presentation format consistent with the evaluation requirements discussed in section 9. All problem evaluations are to be completed at the demonstration site (New Mexico Engineering Research Institute). Documentation requested in Chapter 9 must be supplied within ten days of completing the demonstration. No further computational analysis will be permitted after leaving the demonstration site without extensive justification.

\subsubsection{Demonstration Inspection}

The EPA, BNL, or ORNL will conduct an inspection of all demonstration activities. This activity will document any deviations from the demonstration plan, use of QC materials, operational details, and other factors associated with an evaluation of the Decision Support Software 
technologies. This inspection report will be included as part of the Quality Assurance Project Plan (Section 8.0).

\subsection{Demonstration Schedule}

The Developers will be provided with the pre-demonstration test problem by August 10 . There will be one pre-demonstration problem for each endpoint. The pre-demonstration problems will be distributed to the Developers to test their capabilities to read data files which specify the problem. The pre-demonstration problem will also be used to verify that the Developers have a clear understanding of the types of problem that will be evaluated at the demonstration.

Around August 29, there will be a conference call among all of the Developers and the verification organization. This call will provide a forum for discussing the pre-demonstration test problem and for providing suggestions on how to improve the demonstration. It will also provide a final opportunity to clarify the objectives of the demonstration and the roles of the participants.

Demonstration activities are scheduled to occur between September 14-25. The schedule for this program is provided in Appendix B. 


\subsection{DEMONSTRATION}

This section describes the logistical requirements associated with DSS technology demonstration. This phase of the demonstration requires close communication between the Developers, BNL, ORNL, and the EPA. The implementation of the demonstration must be consistent with the requirements of the study and routine operation of the technology.

\subsection{Communication and Documentation}

Staff from BNL or ORNL will communicate regularly with the demonstration participants to coordinate all demonstration activities and to resolve any logistical, technical, or QA issues that may arise as the demonstration progresses. The successful implementation of the demonstration will require detailed coordination and constant communication among all demonstration participants.

If unanticipated or unusual situations are encountered during the demonstration that may alter the test design, the situation will be discussed with the EPA project manager. Any deviations from the approved final demonstration plan will be thoroughly documented.

All Developer/Verification Organization activities will be thoroughly documented. The verification organization will document the transmittal of all data to the Developers. The Developers demonstration documentation will include the equivalent of field logbooks (i.e., documentation of the assumptions and steps used in the analysis), computer generated output including input files to perform QA checks on proper use of the data, output files documenting the parameters used in the analysis, graphic files to display results, and the summary report documenting all assumptions. Section 9 specifies the documentation requirements for this demonstration.

The Verification Organization field team leaders, Terry Sullivan and Anthony Armstrong, will be responsible for receiving and maintaining all demonstration documentation. Demonstration notes will be kept in a bound logbook which will be supplied to the Developers. Each page will be sequentially numbered and labeled with the problem name and number. Completed pages will be signed and dated in the upper right-hand corner of the page by the individual responsible for the entries. Errors will have one line drawn through them and this line will be initialed and dated.

All computer generated outputs will be logged in the field logbook. These entries will include the time, date, file name, file format (Text, WordPerfect, bitmap, JPG, etc.), contents of the file (e.g., main output file for test problem 1 at Site A, bitmap representation of contaminant concentration levels at time 1 at Site A, etc.), and the identity of the analyst. The Developers are asked to be as specific as possible. Notes about each test problem, method of analysis, computational routines used, etc. will be written in the field logbook. Any agreed upon deviations from the approved final demonstration plan will be thoroughly documented in the field logbook and provided to either Terry Sullivan or Anthony Armstrong. 


\subsection{Data Presentation Procedures}

Prior to the demonstration ORNL and BNL will collect and prepare data sets using the procedures described in Section 6. A master document identifying all data files for the demonstration and a brief description of their contents will be maintained. Any changes to the original data files will be documented in the master document. At the demonstration, ORNL will be responsible for delivering the data to the Developers in an electronic form useful for analysis. Printed copies of the data files will also be made available to the Developers.

In the sample optimization problems, the Developers will be supplied with a limited contaminant characterization data set. From this they will be asked to optimize sample collection activities subject to constraints (for example, determine with $90 \%$ confidence the minimum region of contamination in which the concentration is greater than $50 \mathrm{ppb}$ ). They will use the software to specify additional locations requiring data. At this point, the verification organization will supply the data to the users at either the nearest sampled location, or at the requested location using interpolation of the actual data. All additional data supplied to the users will be documented by the verification organization and the Developers in their demonstration log book.

The Developers will be required to address a minimum of three problems. One problem will be specified by the Organization team, while the other problem can be selected from the other data sets. It is anticipated that time will permit analysis of more than three test problems.

\subsection{Training Requirements}

It is expected that all operators of the DSS will be capable of effectively using the software and will not require special training to conduct this demonstration.

\subsection{Technology Logistical Needs}

The Developers will provide all computer equipment needed for work associated with this demonstration. This will include the computer, monitor, input devices (CD, disk drives, etc.), and interfaces between the computer and peripheral equipment (Internet, printers, etc.). Printers will not be supplied for each Developer, however, at least one printer will be available for use. Attempts to obtain monitors will be made upon request.

The host organization, New Mexico Engineering Research Institute, will supply access to:

- $\quad$ the Internet and file transfer protocol (FTP) sites for transferring the data prepared at ORNL to the demonstration site (New Mexico Engineering Research Institute).

- a Xerox machine (color if possible) for reproducing documentation provided by the Developers.

- a printer(s) (color if possible) to provide paper copies of electronic files.

- a phone line for communication between the Developers and the network server with the data.

- $\quad$ a fax line for communication between the Developers and their home office. 


\subsection{QUALITY ASSURANCE PROJECT PLAN (QAPP)}

The QAPP for this demonstration specifies procedures that will be used to help ensure the quality of this demonstration. Careful adherence to these procedures will help guarantee that data generated from the analyses performed during the demonstration will meet the desired performance objectives and will provide defensible results.

\subsection{Purpose and Scope}

The primary purpose of this section is to outline steps that will be taken by operators of the DSS technologies to ensure that analysis resulting from this demonstration is of high quality and that sufficient support and documentation will be supplied to evaluate the technologies. In environmental problems, the natural variabilities in the system preclude determination of an absolute standard for comparison. There will be uncertainty in each analysis. For this reason, the documentation of the use of the models and assumptions used to generate the analysis is crucial. The documentation supplied by the Developers will form the cornerstone of the evaluation of their technologies.

\subsection{Quality Assurance Responsibilities}

BNL and ORNL staff are responsible for ensuring that the QAPP is followed in this demonstration. The Developers will be responsible for implementing the QAPP during all demonstration activities.

Prior to the demonstration, a series of data sets will be prepared by ORNL to test the different aspects of the DSS. At the demonstration, a single data set will be provided to the Developers for analysis. Upon completion of one problem, the Developer may request another problem to demonstrate other aspects of the software.

QA/QC activities for the DSS technology will include those required by the EPA or the Verification Organization to assure the demonstration will provide data and documentation of the necessary quality. The Developers may recommend appropriate QA/QC procedures for their technology. The majority of the QA/QC work will be the review and analysis of the documentation of the process, input, and output from the analysis performed by the DSS.

\subsection{Data Quality Indicators}

The model predictions obtained during the demonstration must be of sufficient quality for conclusions to be drawn on the ability of the DSS technologies to support environmental decisions. Data quality parameters include four indicators: representativeness, comparability, reproducibility, and accuracy.

Predictions generated by the DSS technologies will be compared to the measured data and the predictions of the baseline analysis. High-quality, well-documented analysis results are essential for meeting the purpose and objectives of this demonstration. Therefore, the following indicators of data quality will be evaluated to determine the performance of the technology. 


\subsubsection{Representativeness}

Representativeness, in general, implies that the DSS will function effectively over a reasonable cross-section of the "population" over which they are to be used to make inferences. In order to test the DSS technology representativeness, care has been taken to select

- $\quad$ multiple sites with unique site history and site characteristics.

- multiple contaminants.

- $\quad$ multiple media (soil and groundwater contamination).

- $\quad$ multiple endpoints (visualization, sample optimization, and cost/benefit analysis).

Sections 4 and 6 discuss the range of test problems in detail. Evaluation for representativeness will be completed by review of the range of problems over which each DSS is applied in this demonstration.

\subsubsection{Comparability}

The analysis from the DSS must be comparable in some way to a reference or baseline method for the demonstration to be worthwhile. In this demonstration, the Developers will be provided with a partial data set. Three approaches will be used to examine the DSS predictions. Comparisons will be made between the DSS predictions and i) the data, ii) a baseline analysis formed from the complete data set, and iii) a baseline analysis performed using the partial data set supplied to the Developers. The comparisons will involve qualitative and quantitative components. Sections 3.2 and 5.4 provide the criteria and methods for comparison.

Discrepancies among the three comparisons will be noted and evaluated. The evaluation will focus on understanding the cause for the discrepancies and determining the impact of the discrepancies on the decision. For example, perhaps the differences can be attributed to use of a different numerical solution procedure. The important point in the evaluation is to determine whether the discrepancies impact the decision. For example, if the decision is to define the volume and location of contaminated material and all approaches provide essentially the same answer, then the method will be viewed as valid. If the discrepancies are large enough such that a substantial disagreement occurs, a thorough evaluation into the cause of the discrepancy will be initiated.

If there are substantial differences in the predictions, attempts will be made to reproduce the assumptions based on the documentation supplied with the analysis. If it is determined that the differences are due to the assumptions, then the DSS method will be valid. If the difference between the data or baseline predictions and the DSS predictions cannot be resolved, this is an indication that the DSS has difficulties with the problem under study.

\subsubsection{Reproducibility}

Reproducibility is a requirement for a high quality software analysis. This will require documentation of all assumptions and data used in the analysis and discussion of major findings and their supporting documentation (i.e., graphical displays, computer output). As discussed above, reproducibility will play a major role in evaluating comparability when differences arise between DSS 
results and the baseline analysis. If the Developer's results cannot be reproduced, there will be no basis for comparison. Reproducibility, or lack thereof, will be noted in the evaluation.

\subsubsection{Accuracy}

Accuracy is a measure of how close, on average, values predicted by the DSS are to the true values. The concern in the DSS demonstration is that in the test cases using actual data, the measured data are the reference "true" data. However, these data are from an uncontrolled experiment in which it is assumed that the measurements are $100 \%$ accurate. This is clearly incorrect. Therefore, although comparisons of the DSS model predictions and the data will be performed, it will not necessarily be a reliable measure of accuracy. This analysis, however, will provide a qualitative comparison of how well the predictions match the data.

Accuracy can be judged based on the problems for which a known solution exists. This arises in two sets of cases. The first is in the location of surface structures, soil boring, and well locations. The second is for synthetic test problems in which the exact values of concentration are known at each spatial location. In these types of problems, accuracy will be evaluated by statistical measures. If inaccuracies are observed in the DSS prediction, the cause of the inaccuracies will be investigated. If it can be traced to an error in translating data into the format needed by the DSS or in conceptual model development during the demonstration, guidance will be provided to the Developers to improve their analysis.

\subsection{Quality Control Checks}

It is assumed that for the purposes of this demonstration all data supplied to ORNL for development of test problems are accurate. Therefore, quality control will only be required on the translation of the data from the sites into test problems, the transfer of the data to the demonstration site, and eventually the distribution to the Developers. ORNL will perform random checks on the data selected for the test problems and compare this to the original data. Documentation of these QC checks will be prepared. Any deviations will be noted and the cause for the deviation will be determined. 
To perform a high quality analysis, specific procedures will be followed during data reduction, validation, and reporting. These procedures are detailed below.

\subsubsection{Data Reduction}

Data reduction refers to the process of converting the raw results from the DSS into an analysis that supports the conclusion of the study. In this demonstration, the data reduction step will be explained as part of the problem documentation supplied through the logbooks, computer outputs and analysis summaries as described in Section 9.

\subsubsection{Data Validation}

The DSS operator will be expected to verify the completeness and correctness of the analysis. Documentation requirements for completeness are specified in Section 9.

Once an analysis is submitted to the Verification Organization, they will review the analysis for completeness. If the analysis is incomplete, the DSS operator will be asked to supply the missing components. All analysis and documentation work is expected to be completed during the demonstration.

\subsubsection{Analysis Reporting}

Documentation is essential to the evaluation of the DSS. Documentation will include a summary report for each test problem analyzed, a logbook documenting the steps in the analysis, and a transmittal report listing all files and documentation supplied to the Verification Organization. The details of the documentation requirements are provided in Section 9.

\subsection{Calculation of Data Quality Indicators}

Quantitative comparisons between DSS predictions and data or baseline predictions will be conducted. These indicators will provide an estimate of how well the predictions match the data. Techniques that may be used to perform the evaluation are the mean average error (MAE), positive mean error (PME), negative mean error (NME), and root mean squared error (RMSE).

The mean average error is defined as the average residual between the measured solution and the DSS solution and is:

$$
M A E=\frac{1}{n} \sum_{i=1}^{n}\left|C_{i, s}-C_{i, m}\right|
$$

Where $\mathrm{n}$ is the number of data points, the subscript $\mathrm{m}$ refers to the measured value and the subscript $\mathrm{s}$ refers to the DSS predicted values. 
The Positive Mean error is a quantitative indicator of the overestimation of the DSS analysis relative to the measured (or baseline) value. It is defined as:

$$
P M E=\frac{1}{n_{p o s}} \sum_{i}^{n_{p o s}} \operatorname{POS}\left(C_{i, s}-C_{i, m}\right)
$$

Where $\mathrm{n}_{\text {pos }}$ is the number of positive differences, and POS refers only to differences greater than 0 .

The Negative Mean Error can also be used to examine for trends in which under-prediction regularly occurs and is evaluated as:

$$
N M E=\frac{1}{n_{n e g}} \sum_{i}^{n_{\text {neg }}} N E G\left(C_{i, s}-C_{i, m}\right)
$$

Where $n_{\text {neg }}$ is the number of negative differences, and NEG refers only to differences less than 0 .

The root mean squared error is a better measure of the overall fit to the data and is defined as:

$$
R M S E=\sqrt{\frac{1}{n} \sum_{i}^{n}\left(C_{i, s}-C_{i, m}\right)^{2}}
$$

In many cases, it will be better to represent the deviation in relation to the maximum concentration in the system. This is the relative error and is expressed as the ratio of an error term, such as the MAE, PME, or RMSE to the maximum concentration in the system. The percent relative error is calculated using the expression:

$$
R E \%=\frac{\text { Measure }}{C_{m, \max }} \times 100
$$

The use of relative error often helps to clarify the magnitude of the error relative to the problem size.

All of these error measures are more sensitive to the regions in which the measure (concentration) is large. For example, having a factor of two difference between the measured and DSS predicted values at a location where the measured value is relatively low will only have a minor impact on the error measure whereas, if this factor of two difference occurs near the peak concentration then it will have a major impact on the estimated error. 
In general, having the error measure most sensitive in the regions of highest concentration is acceptable. However, there may be times when this approach is not effective. For example, if the peak concentration is $10 \mathrm{ppm}$ and the problem is to define the contamination zone near $10 \mathrm{ppb}$, the error measures will not be useful. In this case, other approaches will be used to evaluate the error. These approaches could be normalization of all concentrations by the measured value at that point. For example, the relative root mean squared error is:

$$
R R M S E=\sqrt{\frac{1}{n} \sum_{i}^{n}\left(\frac{C_{i, s}}{C_{i, m}}-1\right)^{2}}
$$

This would give the relative error at each point and places more emphasis on matching each data point. Thus, errors at relatively low concentrations which are unimportant to the decision could be an important contributor to the total error.

To avoid the problem of relatively low concentration values contributing to the measure of the error, the error can be defined over a bandwidth. For example, if the objective of the problem is to define all regions above a concentration level of $10 \mathrm{ppb}$, the error measurement can be evaluated only at points when the measured concentration falls between 1 and $20 \mathrm{ppb}$. This will focus the error measure to evaluate error in the region of highest concern. Development of a bandwidth approach to measuring the error will be performed on an as needed basis.

\subsection{Status Reports}

The Developers and the Verification Organization will periodically report to the EPA project manager. These reports will discuss project progress and problems in the demonstration or evaluation. When problems occur, the Developer and the Verification Organization project managers will discuss them with the EPA project manager, estimate the type and degree of impact, and describe the corrective actions taken to mitigate the impact and to prevent a recurrence of the problems. Written reports will be prepared upon request of the EPA project manager.

\subsection{Demonstration Inspection Report}

The EPA, BNL, or ORNL will conduct an inspection of all demonstration activities. This activity will document any deviations from the demonstration plan, changes to the software, use of QC materials, operational details, and other factors associated with an evaluation of the Decision Support Software technologies. If problems are identified, action will be taken immediately to resolve the issues during the demonstration. A formal report will be prepared for the EPA project manager who will forward the appropriate report to each Developer. 


\subsection{DATA MANAGEMENT AND ASSESSMENT}

The Developers, Verification Organizations (BNL and ORNL), and the EPA each have distinct responsibilities for managing and analyzing demonstration data. The Verification Organization is responsible for managing all the data and information generated during the demonstration. The Developer is responsible for furnishing those records generated by the technology operator. The EPA and the Verification Organization are responsible for analysis and verification of the data.

The Developer is responsible for obtaining, reducing, interpreting, validating, and reporting the data associated with their technology's performance. These data should be reported in printed and electronic format (e.g., computer input/output files, graphical output files, spreadsheets, etc.). To facilitate evaluation, electronic data must be supplied in the same form as any information provided in the demonstration. Test reporting is required for each problem addressed by the DSS technology and is covered by three document types.

- A transmittal report which identifies each piece of information provided to the Verification Organization.

- A demonstration log which is a record of all events and processes that occur during the test. This includes anomalous events such as a "hung" operating system requiring a restart of the computer or deviations from the test plan.

- $\quad$ A demonstration test summary report which summarizes the testing activity, results of the test, and explains the rationale for supporting a decision.

The transmittal report should also contain general information about the DSS system hardware used in the demonstration. This information supplied must include the information in Table 9.1 as a minimum. 
Table 9.1 Example of Information on the DSS System Used in the Analysis

\begin{tabular}{|l|l|}
\hline Software Name & Product- X \\
\hline Version Number (date of executable) & $3.2 \quad$ April, 1998 \\
\hline Price of the Software as tested & $\$ 10,000$ \\
\hline Operating System & Windows '95 \\
\hline Processor and Speed & $266 \mathrm{MHz}$, Pentium II \\
\hline Hard Disk Size & $3.2 \mathrm{~Gb}$ \\
\hline Random Access Memory & $64 \mathrm{Mb}$ \\
\hline Storage Devices (CD, Tape Drives, Floppy Drives) & $\mathrm{CD}$ drive (Read Only) \\
& 3.5 inch 1.44 Mb floppy drive \\
\hline Additional Software used in the demonstration & EXCEL, Version 5.0 \\
\hline Network Card (if used) & \\
\hline Modem Speed (if used) & $56.6 \mathrm{~Kb}$ \\
\hline
\end{tabular}

The demonstration log should include a unique identifier for each test problem attempted, the name of the person operating the software, a brief description of the problem, the modeling approach and assumptions used to address the problem, a summary of results of all model runs, list of input/output files generated during the analysis, and the rationale for changing model parameters in different simulations. It is expected that during the course of the analysis, the software will be used in an iterative process in which the software will be executed and the results analyzed. This information will provide the basis for altering input parameters to improve the solution and the process will be repeated. This iterative process must be documented to provide a basis for evaluating how the results are used to support a decision.

Upon completion of the analysis, a summary report should be provided for each problem that is analyzed. The summary report should include:

- the identifier used in the log book for the demonstration problem.

- $\quad$ name of the analyst.

- $\quad$ reference to ancillary software used in the analysis.

- $\quad$ a brief description of the problem and objectives of the analysis.

- $\quad$ a summary of the assumptions, analysis techniques, and data used in the simulation. This will include definition of the parameters used in the models for statistical evaluation, contouring, flow and transport analysis, etc.

- $\quad$ a summary of the test results, (for sample optimization this will include results which lead to selecting the sample locations).

- $\quad$ maps, plots, and graphs generated by the software to support the data analysis. All visualization output should be labeled and axis and tick marks (or other suitable scaling parameters) should be supplied. 
- $\quad$ estimates for the volume and mass of contamination above specified concentrations, e.g., in the region of the plume which is above $100 \mathrm{ppb}$, the volume is $10^{5} \mathrm{~m}^{3}$ and it contains $10 \mathrm{~kg}$ of the contaminant.

- $\quad$ rationale for supporting the decision, including multiple lines of reasoning used in the analysis.

- $\quad$ input/output files (including graphics files) from simulations that support the decision. The data used to generate the graphics files should be supplied in ASCII format to permit a quantitative comparison of model projections and data. If possible, for interpolated parameters (e.g., contaminant concentration) output should include a data file with location ( $\mathrm{x}, \mathrm{y}, \mathrm{z}$ co-ordinates), parameter value, and time (if applicable).

- $\quad$ estimate of resources to perform the analysis, (level of effort and computational simulation time).

The documentation requested is not meant to be an onerous exercise in exposition. Short declarative sentences and bulleted lists are acceptable. The intent of the documentation is to provide a method to follow the process from taking the data, incorporating it into the software, evaluating model outputs, and supporting the decision. Developers will be allowed a ten day period after completion of the demonstration to prepare the summary report for each problem. During this time, no further analysis may be performed by the software. All results generated by the Decision Support Software and ancillary analysis tools must be supplied prior to leaving the demonstration.

This information supplied by the Developers will be used by BNL and ORNL to evaluate the software against the data and baseline solutions. The criteria for evaluation are discussed in Section 3.2 and 5.4 . 


\section{REFERENCES}

Van der Heijde, P.K.M. and Kanzer, D.A. (1997). Ground-water model testing: Systematic evaluation and testing of code functionality and performance (EPA/600/R-97/007). Cincinnati, OH: National Risk Management, Research Laboratory, U.S. Environmental Protection Agency. 


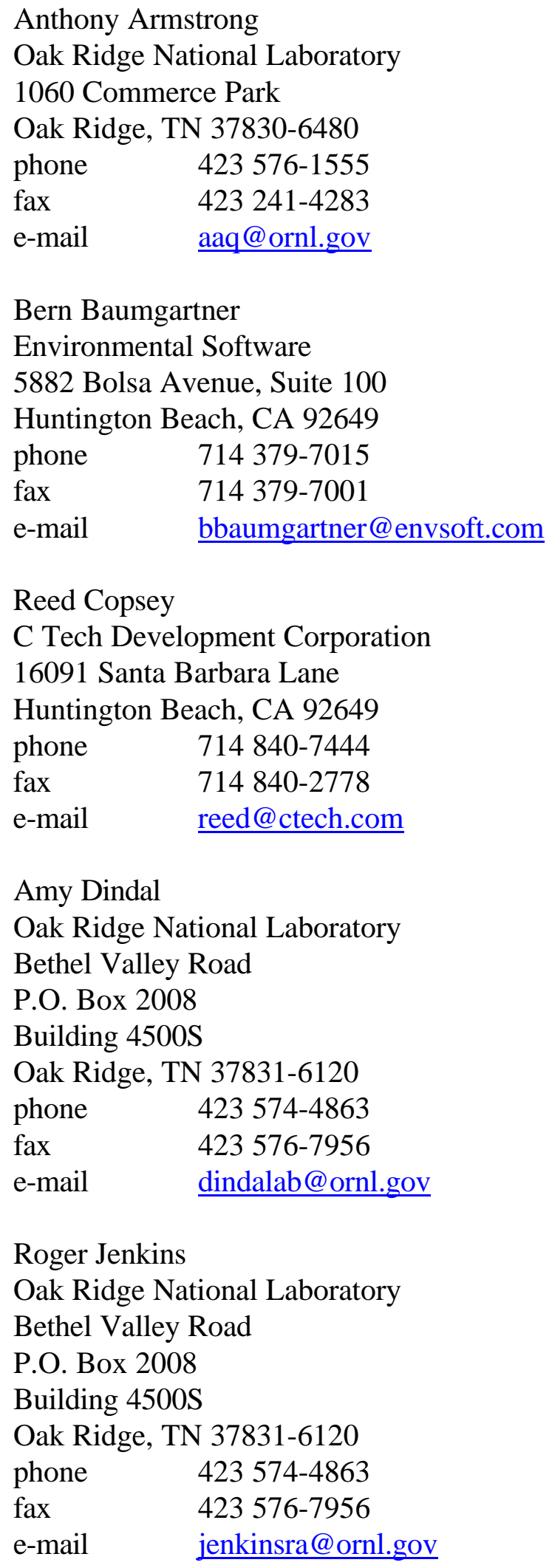




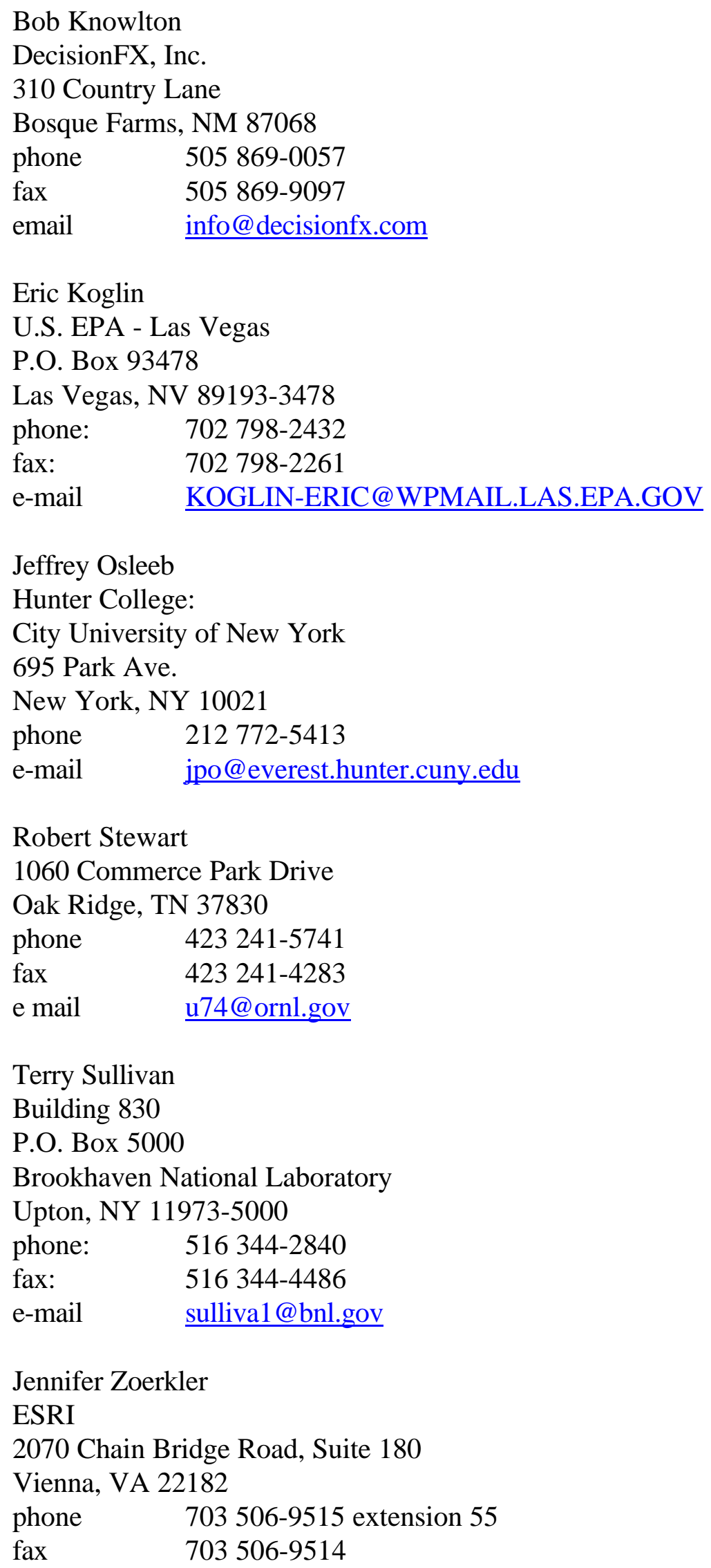

Jennifer Zoerkler

ESRI

2070 Chain Bridge Road, Suite 180

Vienna, VA 22182

phone $\quad 703506-9515$ extension 55

fax $\quad 703$ 506-9514 
email

JZoerkler@ESRI.com 
Appendix B: DSS Demonstration Schedule

\section{Decision Support Software Demonstration Schedule}

\begin{tabular}{|c|c|}
\hline Action & Planned Date \\
\hline $\begin{array}{l}\text { Announcements and call for participants submitted } \\
\text { to various media }\end{array}$ & December 9, 1997 \\
\hline $\begin{array}{l}\text { Generation of potential Developers list and } \\
\text { information for distribution }\end{array}$ & December 19, 1997 \\
\hline $\begin{array}{l}\text { Complete contacts with potential Developers and } \\
\text { compile a list of participants to invite to } \\
\text { Developers conference }\end{array}$ & January 20, 1998 \\
\hline $\begin{array}{l}\text { Distribution of first draft of demonstration plan, } \\
\text { including proposed demonstration design }\end{array}$ & February 10, 1998 \\
\hline Developers conference (hosted by EPA Region 9) & February 18, 1998 \\
\hline $\begin{array}{l}\text { Review of Developers proposals and issue letters } \\
\text { of clarification }\end{array}$ & March 2, 1998 \\
\hline $\begin{array}{l}\text { Final selection of software packages for pre- } \\
\text { demonstration evaluation and notification of } \\
\text { Developers }\end{array}$ & March 11, 1998 \\
\hline Receive letters of intent from Developers & March 20, 1998 \\
\hline CONFERENCE CALL WITH DEVELOPERS \#1 & May 6, 1998 \\
\hline $\begin{array}{l}\text { Preliminary selection of contaminated sites and } \\
\text { data sets }\end{array}$ & May 22, 1998 \\
\hline $\begin{array}{l}\text { Draft demonstration plan distributed for internal } \\
\text { review }\end{array}$ & June 5, 1998 \\
\hline $\begin{array}{l}\text { Complete in-house study to evaluate potential data } \\
\text { sets }\end{array}$ & June 5, 1998 \\
\hline $\begin{array}{l}\text { Receive Internal Review comments on } \\
\text { demonstration plan. }\end{array}$ & June, 17, 1998 \\
\hline $\begin{array}{l}\text { Draft demonstration plan distributed to Developers } \\
\text { for review }\end{array}$ & June 19,1998 \\
\hline
\end{tabular}




\begin{tabular}{|l|c|}
\hline $\begin{array}{l}\text { Receive all Developers comments on the } \\
\text { demonstration plan }\end{array}$ & July 1, 1998 \\
\hline CONFERENCECALL WITHDEVELOPERS \#2 & July 7, 1998 \\
\hline Conduct Pre-demonstration Study & August 10 - 24, 1998 \\
\hline Receive data from the pre-demonstration study & August 24, 1998 \\
\hline $\begin{array}{l}\text { Final selection of contaminated sites and data sets, } \\
\text { including completion of in-house evaluations }\end{array}$ & August 31, 1998 \\
\hline Revise and approve final demonstration plan & Sept 1, 1998 \\
\hline CONFERENCECALL WITHDEVELOPERS \#3 & September 2, 1998 \\
\hline $\begin{array}{l}\text { Conduct demonstration (at NMERI using data sets } \\
\text { from several contaminated sites) }\end{array}$ & September 14 - 25 \\
\hline $\begin{array}{l}\text { Complete draft Innovative Technology Verification } \\
\text { Reports; concurrent EPA review }\end{array}$ & January 7, 1999 \\
\hline Complete Developer review of verification reports & February 5, 1999 \\
\hline CONFERENCECALL WITHDEVELOPERS \#4 & February 7, 1999 \\
\hline $\begin{array}{l}\text { Complete external peer review of verification } \\
\text { reports }\end{array}$ & March 5, 1999 \\
\hline Issue final reports with verification statements & March 26, 1999 \\
\hline
\end{tabular}

